\title{
Heat Transfer in Minichannels and Microchannels CPU Cooling Systems
}

\author{
Ioan Mihai \\ "Stefan cel Mare" University of Suceava \\ Romania
}

\section{Introduction}

The 70-eth of previous century brought the miniaturization of electronic components and the development of systems towards micro and nano manufacturing and in time, more frequent and diverse applications occurred in other domains such as biomedical devices, MEMS and cooling nano technologies. Overheating of these micro components and micro devices led to the use of mini and microchannels in the above mentioned technologies. The aim is to eliminate as fast as possible the maximum heat quantity from these systems in order to ensure an increased reliability and functional stability (Kim \& Kim, 2007). Using CPU's at high temperatures can lower cause system crashes in the short term and in the long term cause the life of your CPU to be greatly reduced. In extreme cases your CPU could burn out or melt onto the motherboard. Evacuation of a large heat flow through conduction and forced convection of the air cannot be adequate achieved by classical methods. Thus, we can conclude that the CPU cooling systems must ensure proper cooling of the CPU. It should be interesting to make a comparative study regarding the maximum values reached by the temperature that develops inside the CPU cores. In figures 1 and 2 we can see the CPU's rated maximum temperature, sometimes called critical temperature.

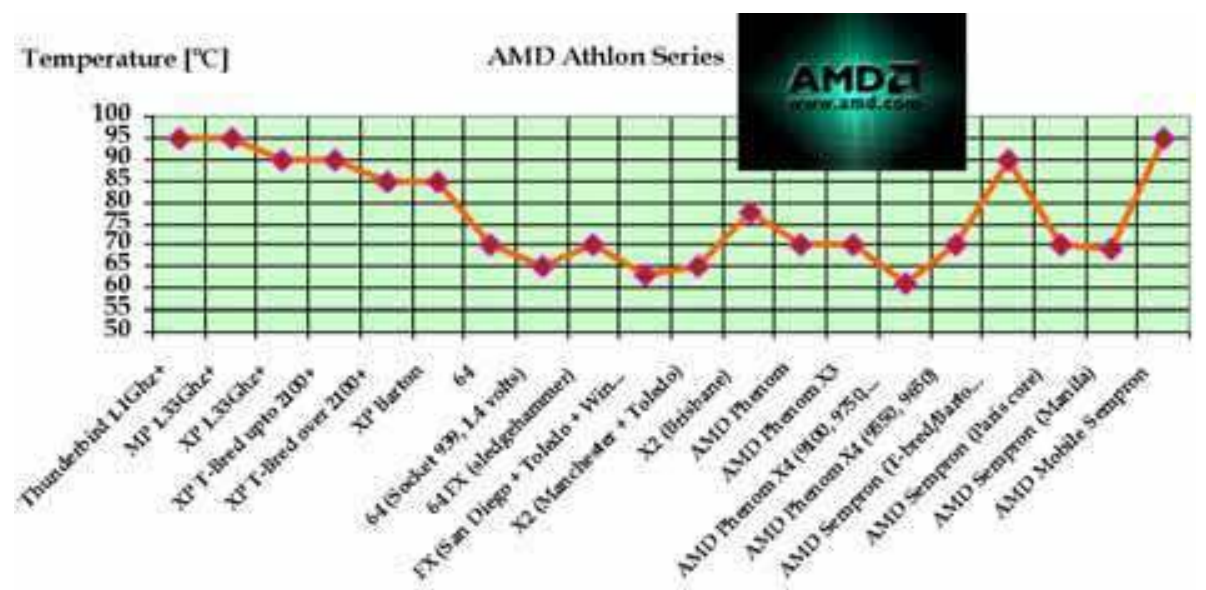

Fig. 1. Critical temperatures for AMD series CPUs 
Due to practical reasons we ascertained that it is recommended to maintain the functional values (indicated by the computer's software) at a value measuring approximately $20{ }^{\circ} \mathrm{C}$ below the maximal values indicated in the two diagrams.

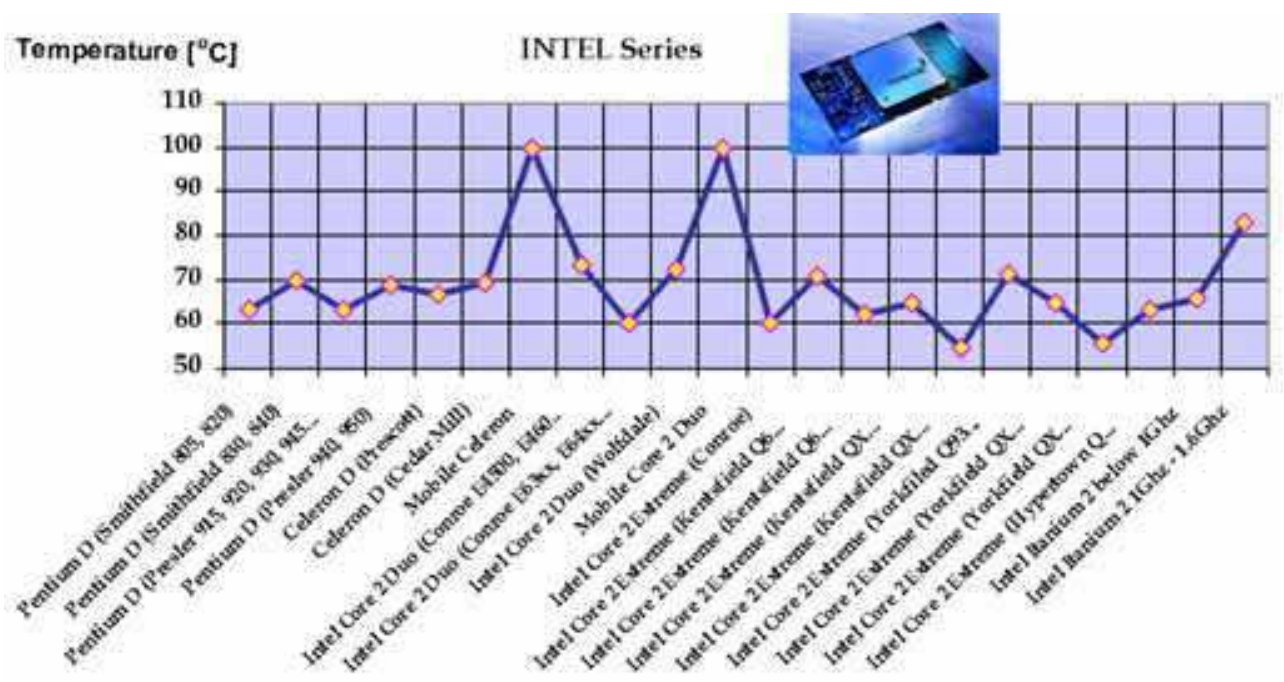

Fig. 2. Maximal values of the temperature for INTEL series CPUs

In both cases we notice that the maximal values of the temperature vary from a maximum of $100{ }^{\circ} \mathrm{C}$, for an Intel Mobile Celeron and Core $2 \mathrm{Duo}$, to a minimum of $54,8^{\circ} \mathrm{C}$ for an Intel Core 2 Extreme (Kentsfield QX6800), whereas for an AMD Athlon CPU we have a maximum of $95^{\circ} \mathrm{C}$ and a minimum of $61^{\circ} \mathrm{C}$, for the Phenom X4 models $(9100,9750,9850)$. Together with CPU development, as it results from Figure 3, the heat flow increases significantly, depending on the frequency variation.

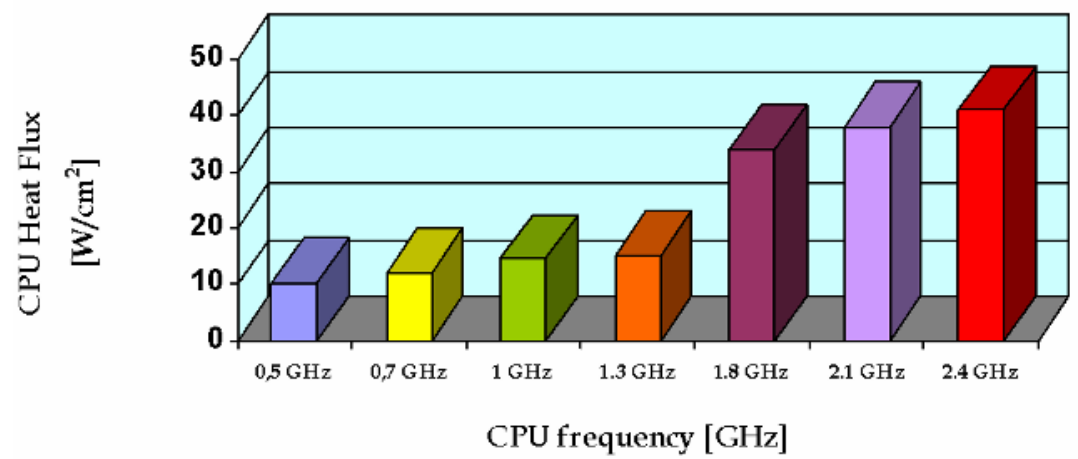

Fig. 3. Heat flow modification depending on the frequency variation

We can emphasize that this increase is exponential. In Figure 4 we show a graphical representation of the temperature flow and the CPU die size variation starting 1975 until the present day. 


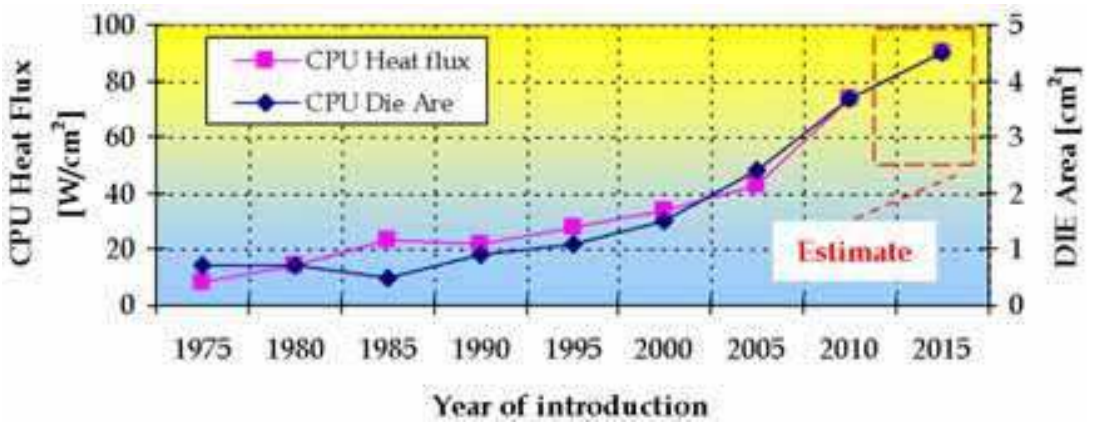

Fig. 4. Variation of the thermal flow and the CPU die size depending on the production year By analyzing the information that was described above, one can observe that, no matter what is the manufactured CPU, an important density of thermal flow develops on the CPU die. High values of the thermal flow imply taking heat dissipation measures. If this requirement is not met then the risk of CPU thermal inducted damage might occur. Therefore, different cooling methods are needed which, under the circumstances of reaching extremely low temperatures, can lead to a significant increase in the CPU's processing speed.

Most recently, the attention was focused on the study of flow processes and heat transfer in microdevices. In these systems (Hadjiconstantinou \& Simek, 2002), the flow and heat transfer processes are of nano and microscopic type and differ as basic mechanism from the macroscopic ones due to dimensional characteristics and molecular type phenomena.

\section{CPU cooling methods and their limits}

Until now (Viswanath et al., 2000, Meijer et al., 2009) indicate two CPU cooling systems, as they are described in Figure 5.

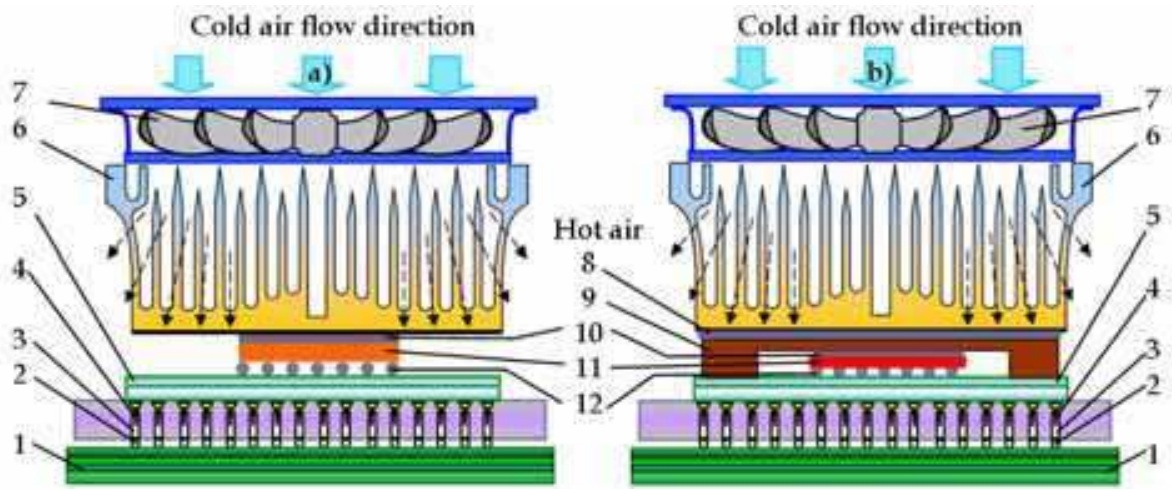

Fig. 5. Types of CPU cooling systems, where: (a) Package with Exposed Die and Heat Sink and (b) Lidded package and Heat Sink

Description of the annotations in Figure 5: 1 - Motherboard planes, 2 - solder ball, 3 Receptacle, 4 - Pin, 5 - Substrate, 6 - Heat Sink, 7 - cooler, 8 - TIM (Thermal Interface Material) 2, 9 - Heat Spreader, 10 - TIM 1, 11 - CPU die, 12 - C4 Solder ball. 
Strictly from a thermal transfer perspective, as (Meijer et al., 2009) also points out, the functions of the described elements are:

- Heat Sink - Dissipates heat to the environment;

- $\quad$ TIM 2 - Transmits heat to the Heat Sink;

- Heat Spreader:

-Evens out heat spot;

-Spreads heat horizontally;

-Protects the die;

- $\quad$ TIM 1 - Transmit heat to the spreader;

- Die:

-Heat generation;

-Hot spot;

The Heat Sink place can be replaced by other cooling systems. A description of these systems (Pautsch, 2005) is represented in Table 1. Also, we mention each one's performance.

\begin{tabular}{|l|c|c|c|}
\hline \multicolumn{1}{|c|}{ Cooling Technology } & $\begin{array}{c}\text { Cray } \\
\text { Product }\end{array}$ & $\begin{array}{c}\text { Power } \\
{[\mathrm{W}]}\end{array}$ & $\begin{array}{c}\text { Power Density Removal } \\
{\left[\mathrm{W} / \mathrm{cm}^{3}\right]}\end{array}$ \\
\hline Air Cooling - Open loop & SV1 & 40 & 127,0 \\
\hline Air Cooling - Closed loop & HPAC & 75 & 203,2 \\
\hline Conduction to Liquid - Cold plate & T3E & 80 & 457,2 \\
\hline Conduction to Liquid - Top Hat & MTA & 100 & 508,0 \\
\hline Single Phase Forced convection (immersion) & T90 & 75 & 381,0 \\
\hline Single Phase Impingement & SS1 & 120 & 762,0 \\
\hline Heat Pipe Assisted Heat Sink & Rainier & 140 & 66,04 \\
\hline Spray Evaporative Cooling & X1/X1E & 200 & 1016,0 \\
\hline $\begin{array}{l}\text { Film Evaporative Cooling } \\
\text { (Spray cooling with Phase Change) }\end{array}$ & Future & 275 & $\begin{array}{c}1397,0 \\
\text { Projected }\end{array}$ \\
\hline
\end{tabular}

Table 1. CPU cooling systems

In addition to the methods described in Table 1 (Banton \& Blanchet, 2004) indicates other possibilities regarding major cooling technology trends, such as:

- $\quad$ Spray cooling with mercury inside - first circa 1999;

- Hollow core liquid cooled electronic modules - Mercury circa 1998;

- Microchannel cooling;

- Refrigeration, air chillers;

- Heat pipes;

- Thermo-electric coolers (TEC).

Recently, development boosted in the area concerning cooling methods that ensure dissipation of increasingly larger power flows. In this respect, (Meijer et al., 2009) indicate various possibilities to increase the cooling process efficiency by either operating on TIM or using one of the following: Ultra Thin High Efficiency Heat Sinks and Manifold Microchannel Heat Sinks, Radially Oscillating Flow Hybrid Cooling Systems, Oscillating Flow Liquid Cooling and the Phonon Transport Engineering method.

A representation of the limits that can be reached by dissipating the heat flow to the maximum is described in Figure 6. In the figure one can observe the CPU cooling methods, the data belonging to (Pautsch, 2005) for the CRAY technologies. 


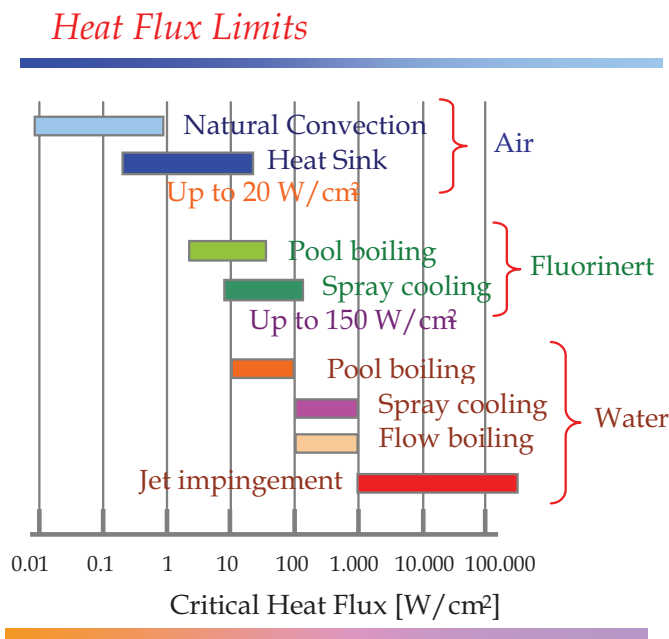

Fig. 6. Maximal values of the Critical Heat Flow (Pautsch) depending on the cooling methods that were used

With respect to the information presented above, we can ascertain that the functioning of a CPU system is extremely complex, and that a direct dependence between working speed and cooling degree exists and it was experimentally revealed in this regard.

\section{Considerations regarding mini and micro channels}

\subsection{Presence of the mini and micro channels within CPU cooling systems}

Heat and mass transfer is accomplished across the channel walls in many man-made systems, such as micro heat exchangers, desalination units, air separation units, CPU cooling etc.A channel serves (Kandlikar et al., 2005) to bring a fluid into intimate contact with the channel walls and to bring fresh fluid to the walls and remove fluid away from the walls as the transport process is accomplished. A classification of the channels conducted by (Kandlikar et al., 2005, Kandlikar \& Grande, 2003) is described in Table 2.

\begin{tabular}{|l|c|}
\hline \multicolumn{1}{|c|}{ Type of channel } & Overall dimensions \\
\hline Conventional channels & $>3 \mathrm{~mm}$ \\
\hline Minichannels & $3 \mathrm{~mm} \geq D>200 \mu \mathrm{m}$ \\
\hline Microchannels & $200 \mu \mathrm{m} \geq D>10 \mu \mathrm{m}$ \\
\hline Transitional Microchannels & $10 \mu \mathrm{m} \geq D>1 \mu \mathrm{m}$ \\
\hline Transitional Nanochannels & $1 \mu \mathrm{m} \geq D>0.1 \mu \mathrm{m}$ \\
\hline Nanochannels & $0.1 \mu \mathrm{m} \geq D$ \\
\hline
\end{tabular}

Table 2. Channel classification scheme (Kandlikar et al., 2005); $D$ value represents the smallest channel dimension.

Increasingly advanced technologies implemented in order to cool the CPU are using, under various types, mini or micro channels. Thus, (Escher et al., 2009) suggests using the UltraThin Manifold Micro-Channel Heat sink; in Figure 7a one can observe the working criterion and, in Figure 7b, a SEM image of the micro channels. 


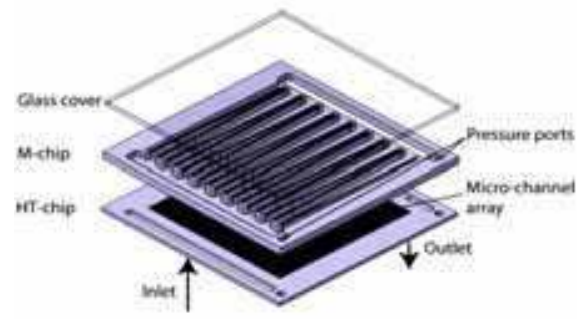

(a)

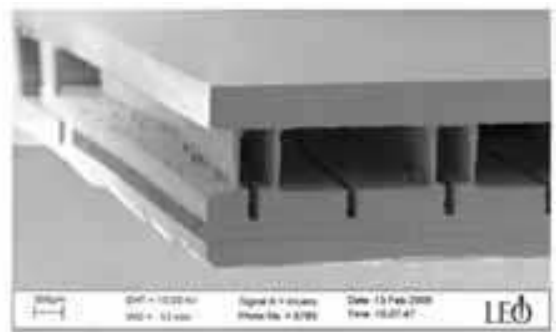

(b)

Fig. 7. Micro channels used within CPU systems (Escher et al., 2009): (a) basic schematics; (b) SEM image of the micro channels

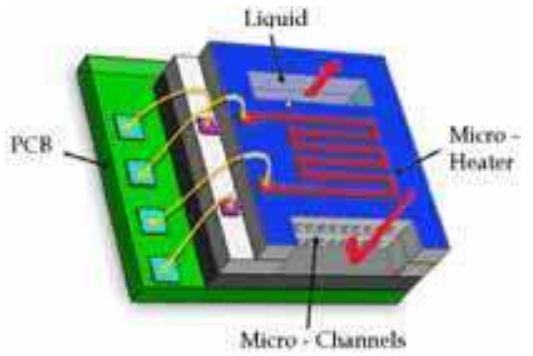

Fig. 8. Pyramid chip stack

The usage of the micro channels in the CPU systems is reminded by (Meijer et al., 2009) for the structures type Pyramid chip stack.

In Figure 8 we present such a structure, emphasizing on the micro channels that are present in the lower part.

IBM Zurich Research Laboratory in 2009 in its research report (Meijer et al., 2009) presents images of the micro channels that can be found in Figure 9.
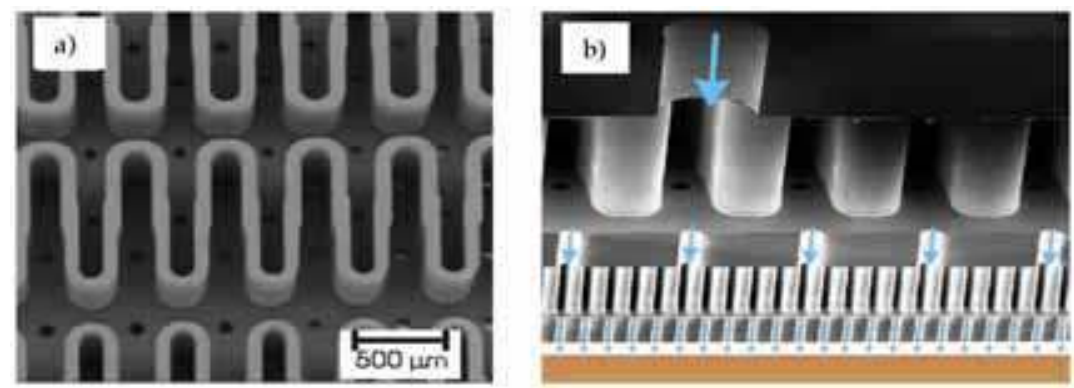

Fig. 9. Micro channels: (a) overview of the micro channels, (b) SEM cross-section of two-level jet plate with diameter of $35 \mu \mathrm{m}$

Inside the Heat transfer laboratory of the "Stefan cel Mare" University of Suceava, Romania, we developed mini heat exchangers that integrate micro channels. Image 10a shows a plate from a mini heat exchanger and image $10 \mathrm{~b}$ shows an AFM image $(19.7 \times 80.0 \mu \mathrm{m})$ of a micro channel. Also, image 10b shows, on the right size, the threshold corresponding to the copper 
material and, on the left side, the threshold corresponding to the composite material. In figure 10c the graph shows the values measured by the AFM.
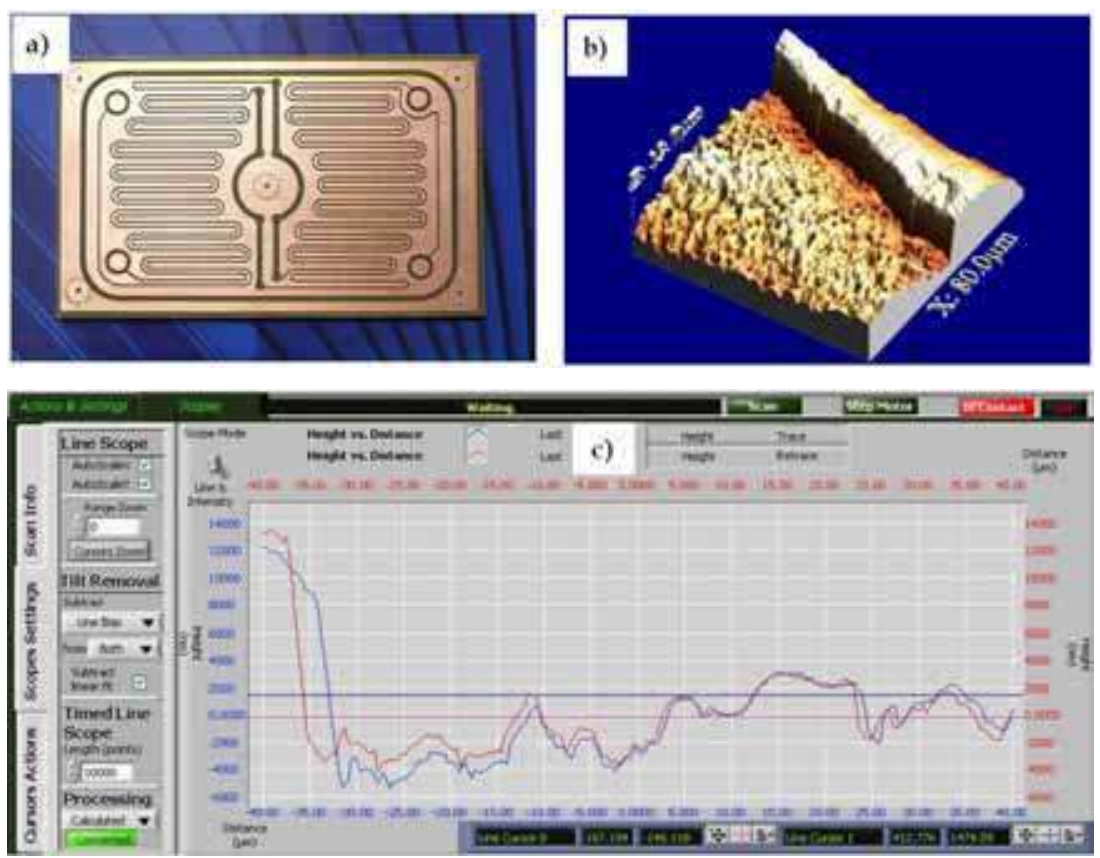

Fig. 10. Images specific to a mini heat exchanger with micro channels: (a) plate, (b) AFM image, (c) AFM graph with measurement data

The data in diagram 10.c show a difference between the lower part of the 1250nm channel and the maximum limit which corresponds to the $13600 \mathrm{~nm}$ copper surface. This indicates a medium micro channel height of $14850 \mathrm{~nm}$. In order to perform accurate surface topography measurements under various conditions, a Nanofocus $\mu$ scan laser profilometer was employed. The images that were obtained for the micro channels, and a detail image, can be seen in Figure 11.

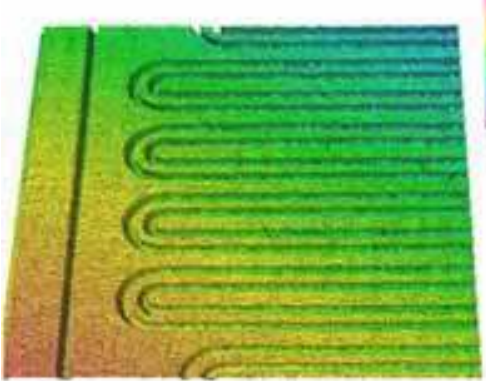

(a)

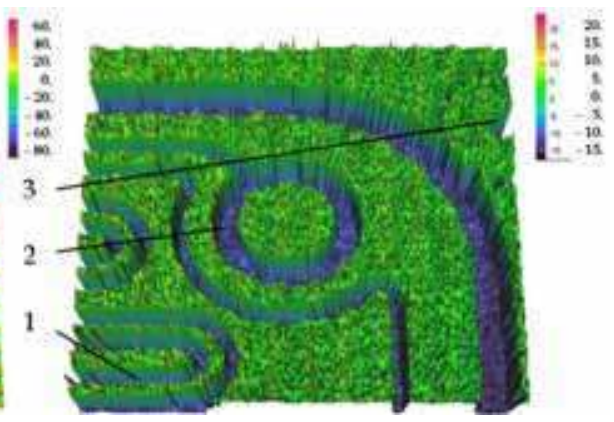

(b)

Fig. 11. Images obtained with the Nanofocus $\mu$ scan profilometer: (a) micro channels, (b) micro channels detail image, were: 1 - microchannels, 2 - admission channelling, 3 - centre holes 


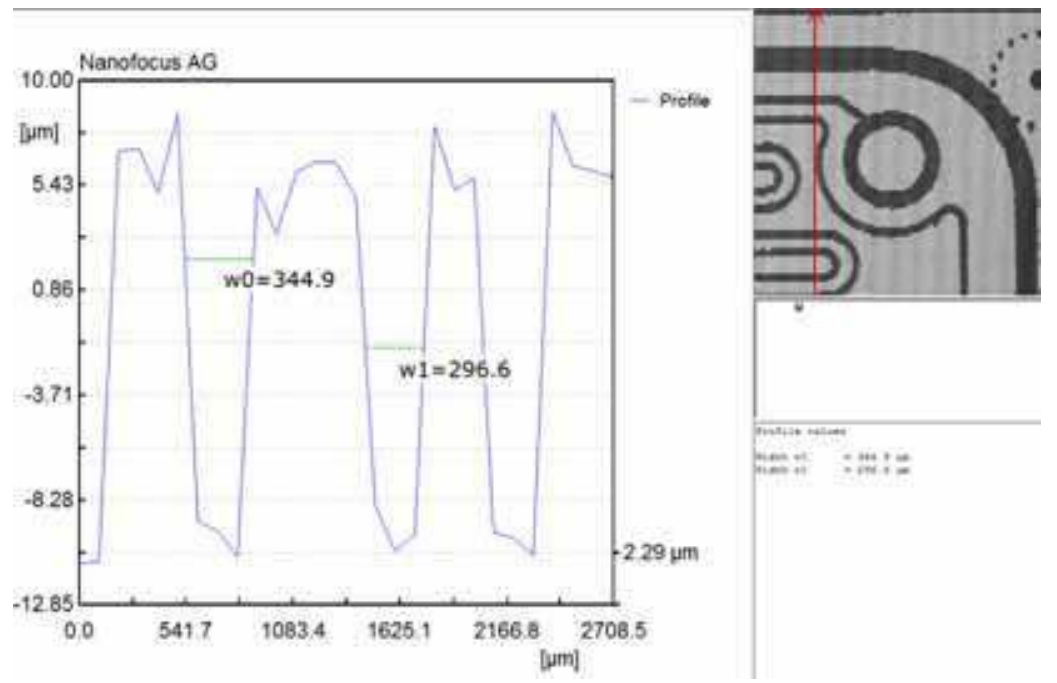

Fig. 12. Heat exchanger micro channels parameters that were obtained with the help of a Nanofocus $\mu$ scan profilometer

The values obtained with the help of a profilometer, as they are described in figure 12, indicate a height approximately equal to the one indicated by the AFM, resulting in an average of $14,85 \mu \mathrm{m}$ which is practically doubled by overlapping two plates. The width of a micro channel measured at the middle point of its height is $296.6 \mu \mathrm{m}$.

From what was described above we can ascertain that mini and micro channels are often used in various areas, one of them being CPU cooling.

\subsection{Experimental evidence of defects occurred in interface layer of cooler-CPU}

When the contact between two surfaces is imperfect, the specific thermal resistance of interface layer suddenly increases, so it became of frequent use to apply diverse materials between the CPU and radiator. Previous research showed that when applied in thin layers, CPU thermal grease may form micro and nanochannels on the surface. These can have a significant impact on the heat transfer between CPU and the cooling system radiator. These materials should both fill the gaps occurred due to surfaces roughness, material's fatigue, loading pressure etc. and transfer as much heat as possible during a short period of time (Mihai et al., 2010).

Inside the Heat transfer laboratory of the "Stefan cel Mare" University of Suceava, using an atomic force microscope AFM-universal SPM, Park Scientific instruments firm, processing unit module SPC 400, electronic control unit SFM 220A, we scanned the interface layer of different processors. The images obtained for an AMD processor are presented in Figures 13a (scale $1 \times 1 \mu \mathrm{m}$ ) and $13 \mathrm{~b}$ (scale $1.6 \times 1.6 \mu \mathrm{m}$ ) respectively.

By analyzing the obtained images, with the help of the AFM, two aspects can be ascertained. Thus, from Figure 13a one can observe that flowing channels may occur in interface layer, having in this case, an estimated width of only $2 \mu \mathrm{m}$ for a height of $2000 \AA$. The second assertion can be deducted from Figure 13b, the appearance of the steady flow zones being clearly visible. Whatever the situation is, a change in the CPU-TIM-cooler contact appears, change which leads to the alteration of the heat exchange transfer. First, a special attention is 
paid to assess the effect of mechanical and thermal properties of the contacting bodies, applied contact pressures and surface roughness characteristics as well as the use of different thermal interface materials on the maximum temperature experienced by the CPU. Second, it can be appreciated that good wetting of the mating surfaces and the retention of asperity micro-contacts can become critical elements in effectively removing the heat generated by the CPU (Mihai et al., 2010). It is commonly recognized that roughness effect can have an impact on microchannel and microtube performance, both in terms of pressure drop and heat transfer. From those described above we can deduct that, if modifications in the TIM layer appear due to a faulty installation, inadequate push pressure values, material aging, faulty TIM appliance techniques, too high temperatures in its exploitation etc., the thermal conduction coefficient and, subsequently, the thermal resistivity changes, leading to CPU damage.
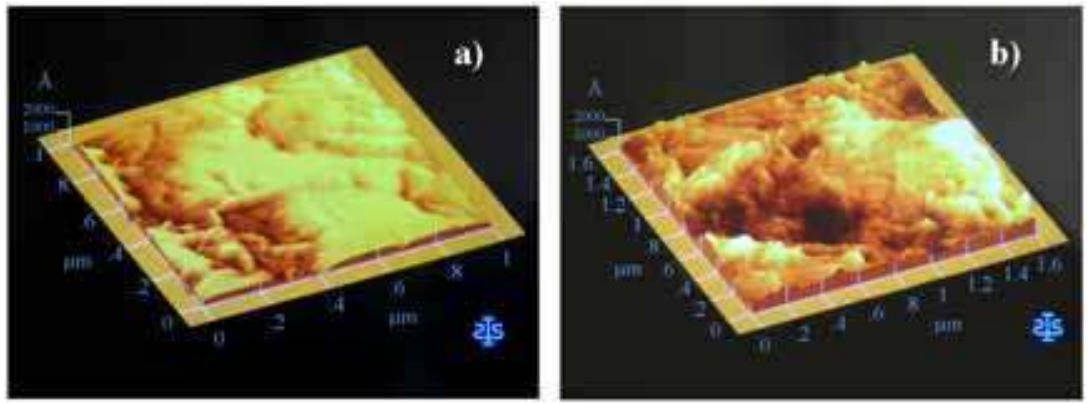

Fig. 13. (a) (b) AFM images of interface layer CPU - Heat Sink: (a) - with the micro channels highlighted, (b) - with the concavities and protuberances emphasized

\subsection{Aspects regarding TIM dilatation}

In the Heat Transfer Laboratory from the Suceava University, a test rig was conceived and built (Figure 14a) in order to study CPU thermal grease behaviour when subjected to high temperatures, close to those leading to CPU failure.
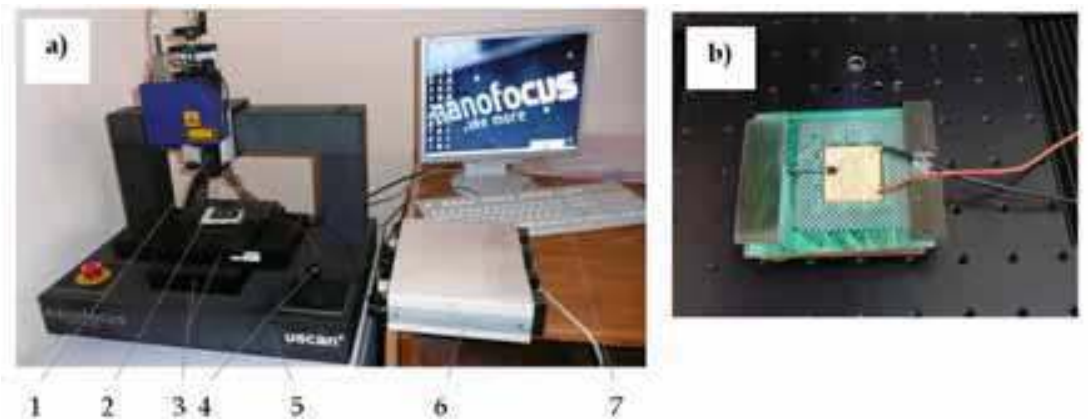

Fig. 14. (a) Test rig Image and (b) CPU and heating system

The description of the annotations in Image 14a is: 1 - laser head, 2 - CPU, 3 - work bench with coordinates, 4 - joystick, 5 - stand, 6 - DC Power supply for the resistors, 7 - nanofocus software. In order to simulate the CPU heating process, under the CPU were mounted 3 
electric resistors. The assembly allows reaching a maximum temperature of $110^{\circ} \mathrm{C}$. A thin layer of thermal grease Keratherm Thermal Grease KP97 is applied on the CPU surface and then the temperature is gradually elevated. After the thermal condition is stabilized, the layer is subjected to profilometer scanning. The surface micro-topography is then analyzed for thermal grease volume and surface variations shown.
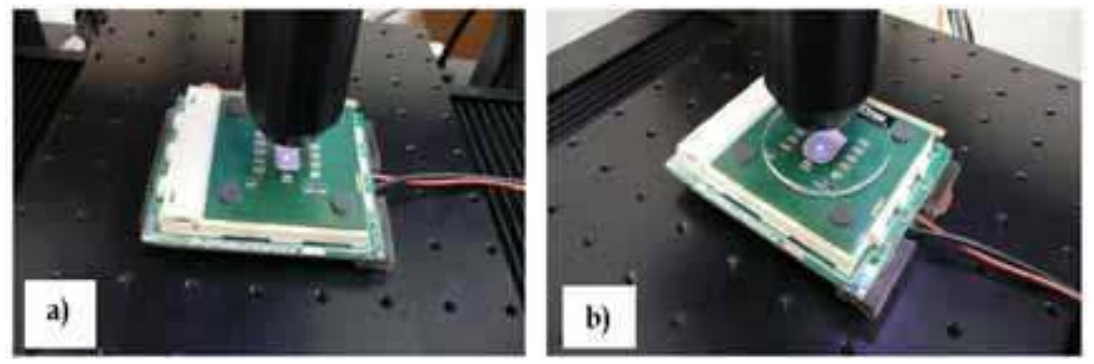

Fig. 15. Experimental investigations of thermal grease layer. (a) without crystal glass and (b) with crystal glass

The experimental determinations were conducted for three hypotheses:

- $\quad$ CPU without a thermal grease layer applied;

- CPU with a thermal grease layer applied (Figure 15a);

- Having a 2,7 mm crystal glass plate placed on the thermal grease covered CPU (Figure $15 \mathrm{~b}$ ), and a $12,5 \mathrm{~N} / \mathrm{cm}^{2}$ pressure applied in order to simulate cooler interface.

For the last two hypotheses, changing the voltage of the power supply led to the three resistors heating up to various predetermined values. The temperature was measured at the surface of the TIM material and CPU with the help of a laser thermometer.

During experimental measurements, several issues were investigated:

- In order to analyze TIM behaviour we simulated the CPU functioning with freshly deposited thermal grease on the surface;

- investigations on whether or not micro or nanometer channels appear in an incipient phase at the TIM surface during its heating stage;

- emphasizing the "pump-up" occurrence of the TIM caused by the expansion effect;

- detection of surface discontinuities appearing during heating (localized lack of material);

- monitoring thermal grease layer profile shape, roughness and waviness evolution.

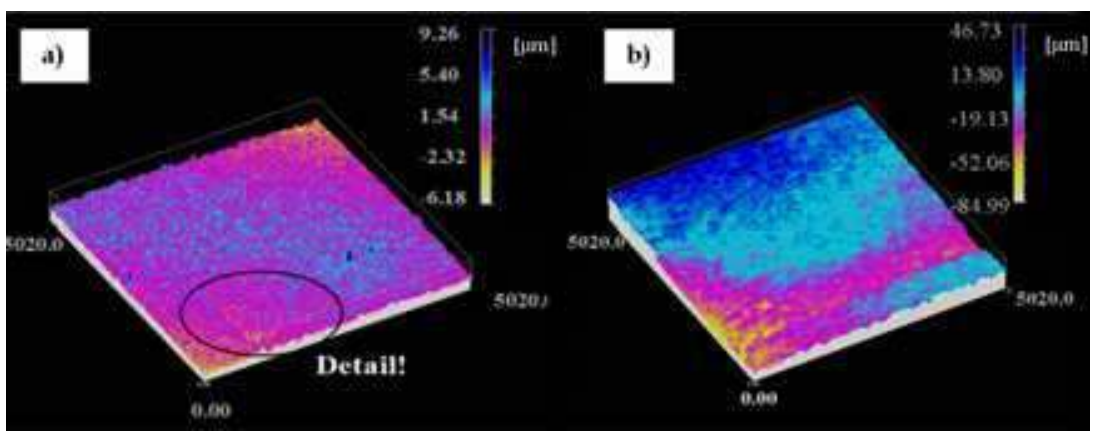

Fig. 16. (a) CPU without thermal grease; (b) Thermal grease layer at $20^{\circ} \mathrm{C}$ 
Next we will describe the images that were obtained by using the assembly specified in Figure 14a. On the left side image of figure 16a, a 3D image of the CPU surface obtained by laser profilometry is shown without the TIM being applied. In Figure 16b, on the CPU surface, a thermal grease layer was applied. It can be observed that, in contrast with the hypothesis described in Figure 14a, the asperity of the surface is modified.

The detail from Figure 16a allows observing the AMD sign. In Figure 17 the profile shape alteration is shown together with the heating of the CPU and, subsequently, the heating of the thermal grease surface.

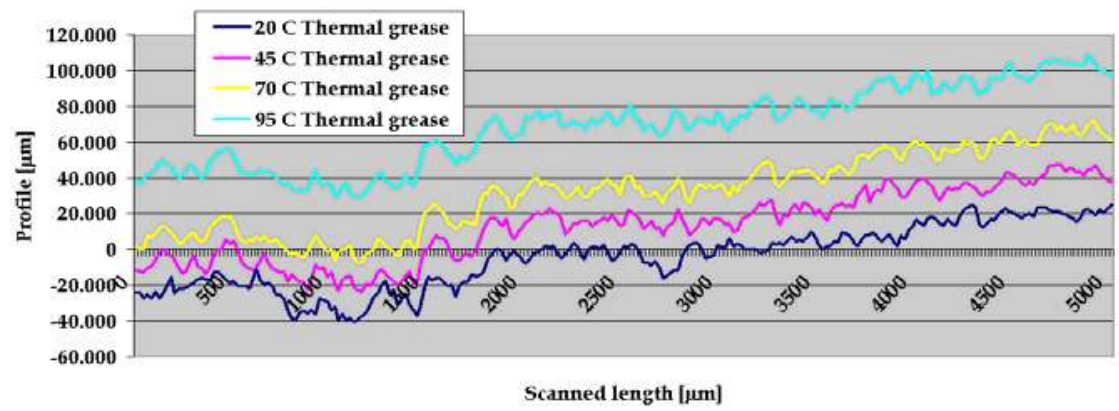

Fig. 17. Profile Shape variation depending on the temperature that was obtained by laser profilometry

The results obtained by profilometry of the applied thermal grease paste are shown in Figures $18 \mathrm{a}, \mathrm{b}$ and for the roughness and waviness, for temperatures of $20,45,70$ and $95{ }^{\circ} \mathrm{C}$, in Figures 19a,b.

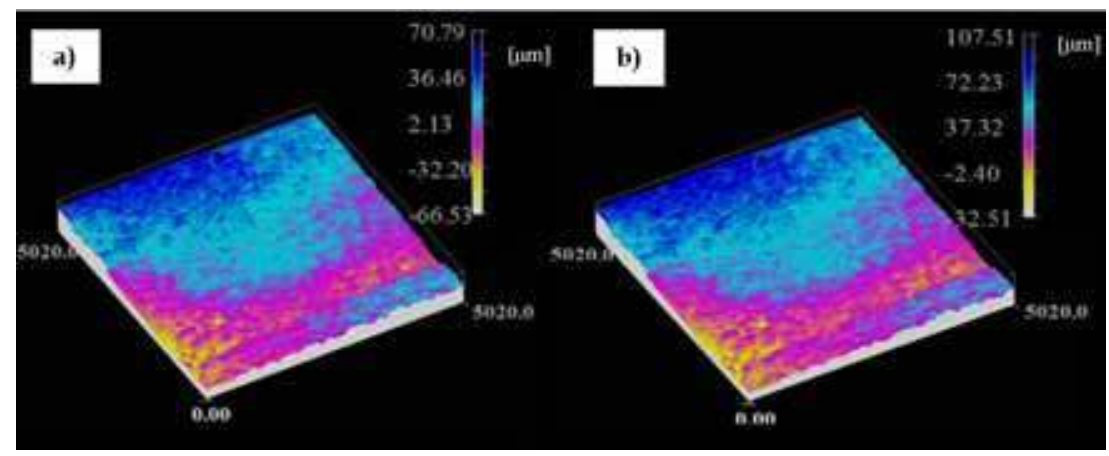

Fig. 18. Thermal grease layer at: (a) $45^{\circ} \mathrm{C}$ and (b) $95^{\circ} \mathrm{C}$

For the second instance we applied a crystal glass over the TIM layer, the crystal glass being pushed downwards with a pressure measuring the same value that we previously mentioned.

The reason in using this crystal glass is brought about by our desire to simulate the TIM behaviour under heat, when flattening the heat sink irregularities in a real case scenario. In Figure 20 we show the images that were obtained by profilometry. 

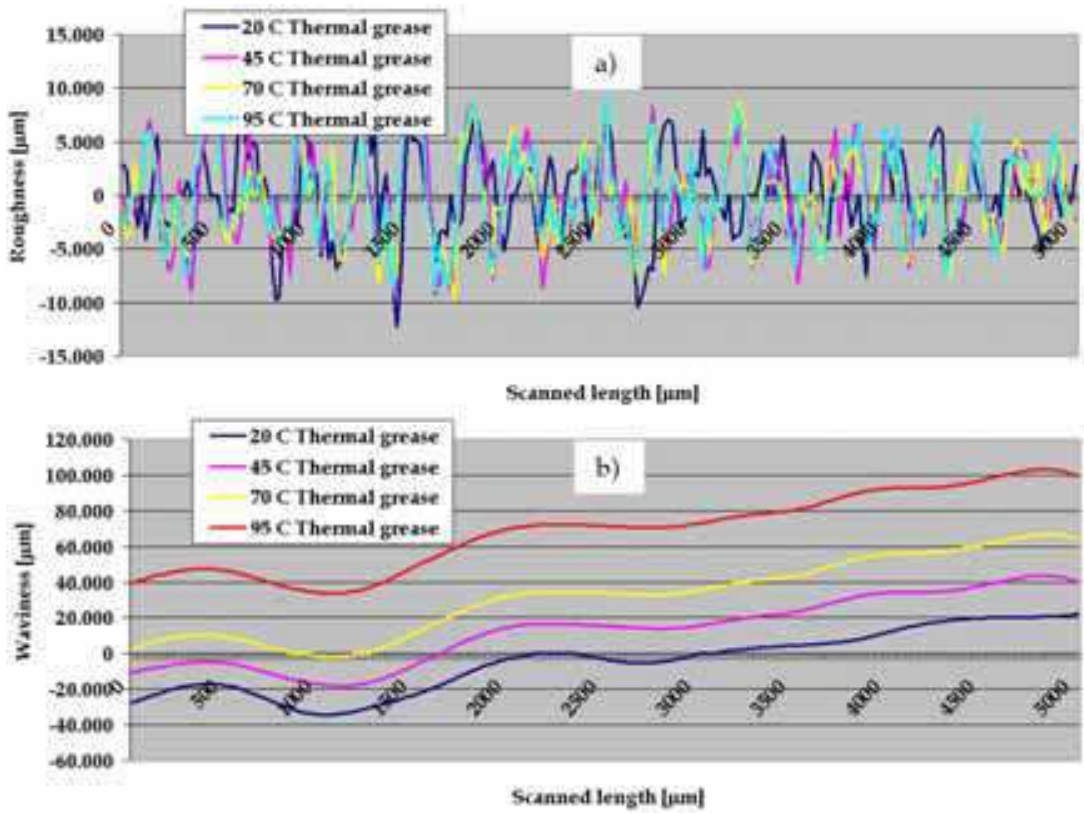

Fig. 19. The results obtained by profilometry for TIM. (a) roughness and (b) waviness

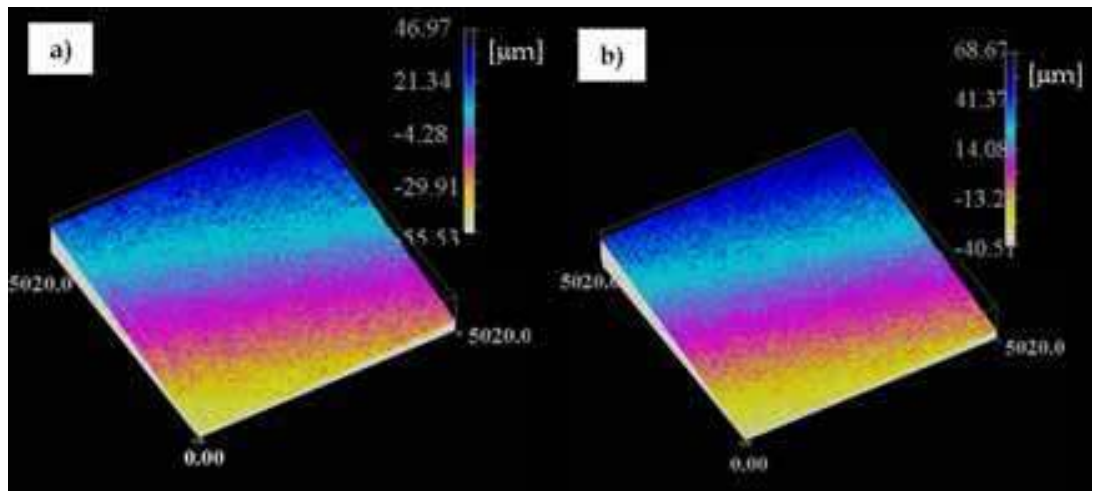

Fig. 20. Thermal grease under crystal glass: (a) at $20^{\circ} \mathrm{C}$ and (b) at $95^{\circ} \mathrm{C}$

Images $20 \mathrm{a}$ and $20 \mathrm{~b}$ show the variation in the roughness size when putting the TIM under pressure caused by an object with a low irregularity coefficient. The detailed results of the Profile Shape size are described in the diagram from Figure 21.

It can immediately be noticed that variations in thermal grease layer profile are considerably smaller after placing the crystal plate, by comparison with the free surface situation.

In order to compare how the same material reacts when is subjected to a heating process, having a much lower initial roughness, we drew graphs for roughness and waviness obtained with the help of the laser profilometer. These values can be observed in Figure 20 . 


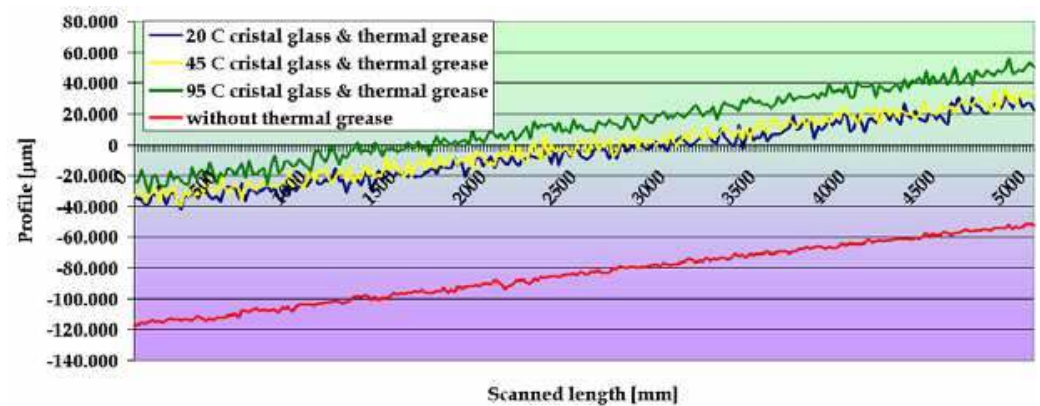

Fig. 21. The change in the Profile Shape size when the crystal glass was applied over the thermal grease

In order to compare the different behaviours of the same material, having an initial much lower roughness, when it is subjected to a heating process, we drew graphs for the roughness and waviness values that were obtained with the help of the laser profilometer. These values can be analyzed in figure 22 .
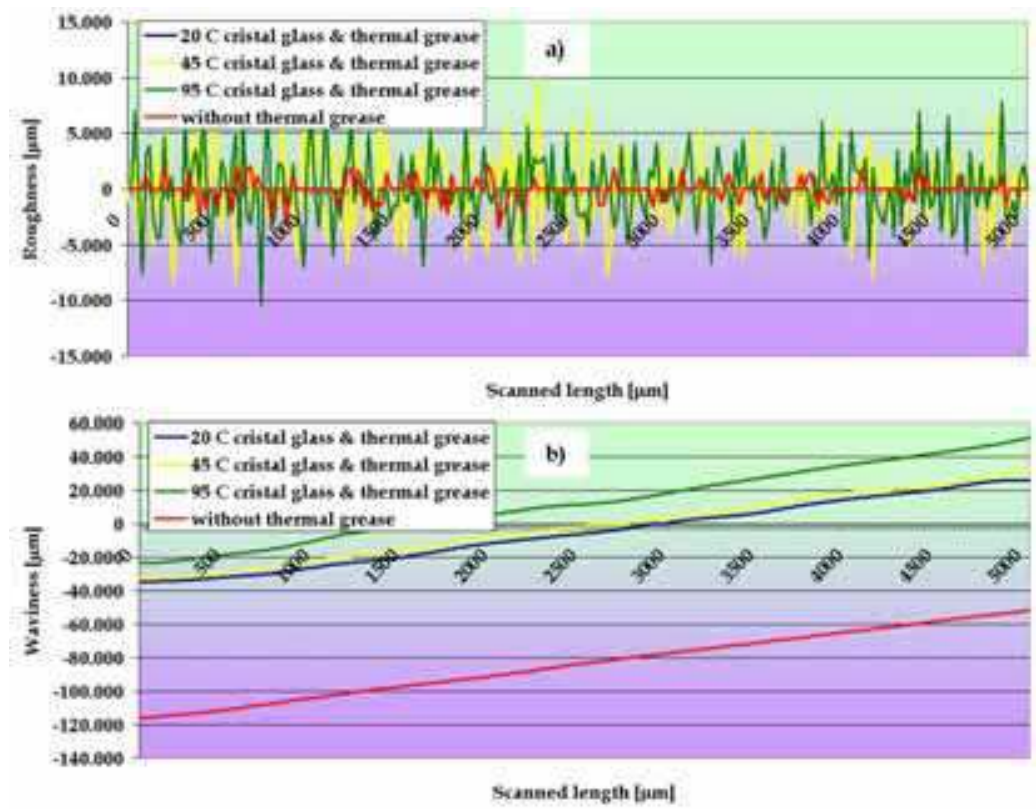

Fig. 22. Results obtained for TIM under a crystal glass. (a) Roughness and (b) Waviness

\section{Heat exchange in the mini, micro and nano channels of the CPU cooling systems}

\subsection{Assessment of flowing regime}

Most recently, the attention was focused on the study of flow processes and heat transfer in microdevices. In these systems, the flow and heat transfer processes are of nano and 
microscopic type and differ as basic mechanism from the macroscopic ones due to dimensional characteristics and molecular type phenomena. The early transition from laminar flow to turbulent flow, and the several times higher friction factor of a liquid flowing through microchannel than that in conventional theories. Heat transfer for a developing compressible flow was studied by (Kavehpour et al., 1997), using the same firstorder slip flow and temperature jump boundary conditions as in heat transfer for a fully developed incompressible flow. The flow was developing both hydrodynamically and thermally and two cases were considered: uniform wall temperature or uniform wall heat flux. Viscous dissipation was neglected, but the compressibility of the working agent was taken into account. We can ascertain that Navier-Stokes and energy equations are inappropriate for micro or nano channels because of failure of the continuum assumption for micro flow. Different computational methods were developed; however, up to date, two main directions in the literature (Kandlikar et al., 2005) are known:

- the working fluid is considered as a collection of molecules;

- the fluid is considered an indefinitely divisible continuum.

The continuum model is usually used in modelling macrosystems. In order to perform the calculus relating to the micro channels of a heat sink it is necessary to take into account a series of parameters, such as: flow rate of the cooling fluid, temperature of the fluid and the channel wall, inlet and outlet pressure required for cooling fluid, hydraulic diameter of the channel, number of channels. Flowing regime in micro and nano channels is usually estimated by means of Knudsen number, given by the relation:

$$
K n=\frac{k}{H}
$$

where $k$ is the mean free path and $H$ is the characteristic dimension of the flow. In time, depending on the values of Kn number, (Kandlikar et al., 2005, Niu et al., 2007, Hadjiconstantinou \& Simek, 2002), several computing models presented in Table 3 were completed.

\begin{tabular}{|c|c|l|}
\hline $\begin{array}{c}\text { Knudsen } \\
\text { number }\end{array}$ & Regime & \multicolumn{1}{c|}{ Navier-Stokes equations viability } \\
\hline $\mathrm{Kn}<0.001$ & $\begin{array}{c}\text { "Continuu } \\
\mathrm{m} \text { " }\end{array}$ & $\begin{array}{l}\text { Accurately modelled by the compressible Navier-Stokes } \\
\text { equations; classical no-slip boundary conditions }\end{array}$ \\
\hline $0.001<\mathrm{Kn}<0.1$ & "Slip-flow" & $\begin{array}{l}\text { Navier-Stokes equations applicable; a velocity slip and a } \\
\text { temperature jump considered at the walls, as rarefaction } \\
\text { effects become sensitive at the wall first. }\end{array}$ \\
\hline $0.1<\mathrm{Kn}<10$ & "Transition" & $\begin{array}{l}\text { The continuum approach is no longer valid; the } \\
\text { intermolecular collisions are not yet negligible and } \\
\text { should be taken into account. }\end{array}$ \\
\hline $\mathrm{Kn}>10$ & $\begin{array}{c}\text { "Free- } \\
\text { molecular" }\end{array}$ & $\begin{array}{l}\text { Intermolecular collisions are negligible compared to } \\
\text { collisions between the gas molecules and the walls. }\end{array}$ \\
\hline
\end{tabular}

Table 3. Flow regimes for different Kn Numbers

From calculus it resulted that the heat transfer coefficient takes extremely great values. The justification is based on extremely small valued of hydraulic flowing diameter.

Obviously, a decrease of hydraulic diameter leads to:

- diminished flow and consequently reduced fluid flowing capacity; 
- diminished heat transfer phenomenon, leading to increase of temperature values.

As Knudsen number increases, fluid modelling is moving from continuum models to molecular models.

Until now (Kandlikar et al., 2005), a series of collision models were developed for the inverse power law (IPL) condition:

- HS - The simplest collision model is the hard sphere (HS) model, which assumes that the total collision cross-section is constant and for which the viscosity is proportional to the square root of the temperature. Actually, the HS model may be described with the exponent $\eta=\infty \rightarrow$ and $\omega=1 / 2$.

- VHS - Bird, who proposed the variable hard sphere (VHS) model for applications to the Monte Carlo method (DSMC), has improved the HS model. The VHS model may be considered as a HS model with a diameter $d$ that is a function of the relative velocity between the two colliding molecules.

- $\quad$ MM - Another classic model is the Maxwell molecules model with $\eta=5$ and $\omega=1$. Actually, the HS and the MM models may be considered as the limits of the more realistic VHS model, since real molecules generally have a behaviour which corresponds to an intermediate value $1 / 2 \leq \omega<1$.

- VSS - Koura and Matsumoto (1991; 1992) introduced the variable soft sphere (VSS) model, which differs from the VHS model by a different expression of the deflection angle taken by the molecule after a collision. The VSS model leads to a correction of the mean free path and the collision rate values (less than 3\%). For $a=1$, the VSS model reduces to the VHS model.

\subsection{Applications of heat transfer through rectangular micro and nano channels in the case of compressible fluids}

As initial statements, on consider that the fluid properties do not modify in time, the fluid is compressible and the flow is of hydrodynamic type. The mathematical model chosen for calculus considers the walls with steady thermal flow. Up to date, two main assumptions are used for computing:

- walls with steady thermal flow;

- constant temperature of the walls.

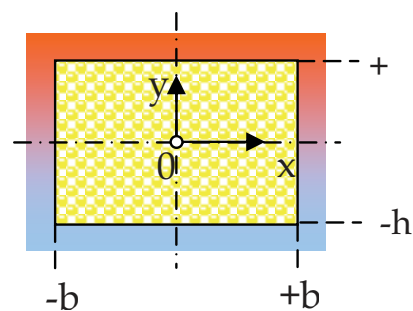

Fig. 23. Rectangular Channel

MathCad application was used in computing. The computing model is VSS and HS as proposed by (Kandlikar et al., 2005). A rectangular channel is considered, as seen in Figure 23 , having the dimensions: $2 \mathrm{~b}=0,4 \cdot 10^{-6} \mathrm{~m}, 2 \mathrm{~h}=0,2 \cdot 10^{-6} \mathrm{~m}, \mathrm{l}=4,7 \cdot 10^{-3} \mathrm{~m}$, through which air flows. The inlet and outlet pressures taken into account for computing are presented in Table 4. 


\begin{tabular}{|c|c|c|c|c|c|c|c|c|}
\hline \multicolumn{1}{|c|}{ Pressure $\left[\mathrm{N} / \mathrm{m}^{2}\right]$} \\
\hline $\mathrm{p}_{\text {outlet }}$ & $p_{\text {inlet } 1}$ & $p_{\text {inlet } 2}$ & $p_{\text {inlet 3 }}$ & $p_{\text {inlet 4 }}$ & $p_{\text {inlet } 5}$ & $p_{\text {inlet 6 }}$ & $p_{\text {inlet 7 }}$ & $p_{\text {inlet } 8}$ \\
\hline 1,001 & $1,006 \cdot$ & $1,225 \cdot$ & $1,450 \cdot$ & $1,675 \cdot$ & $1,900 \cdot$ & $2,125 \cdot$ & $2,350 \cdot$ & $2,575 \cdot$ \\
$\cdot 10^{4}$ & $10^{4}$ & $10^{4}$ & $10^{5}$ & $10^{5}$ & $10^{5}$ & $10^{5}$ & $10^{5}$ & $10^{5}$ \\
\hline
\end{tabular}

Table 4. Inlet and outlet pressure

The viscosity coefficient for air was consider $\omega=0.77$, the exponent for VSS model $\alpha=1,36$, the dynamic viscosity $\mu_{0}=171,910 \times 10^{-7} \mathrm{~Pa} \cdot \mathrm{s}$, the molecular mass $\mathrm{M}=28,9710 \times 10^{-3} \mathrm{~kg} / \mathrm{kmol}$, and the specific constant $\mathrm{R}=9,907 \times 10^{3} \mathrm{~J} / \mathrm{kg} / \mathrm{K}$. An even temperature of $\mathrm{T}=365 \mathrm{~K}$ was considered for the wall. The viscosity was computed for $\mathrm{T}, \mu(\mathrm{T})=20,702 \times 10^{-6} \mathrm{~Pa} \cdot \mathrm{s}$, coefficient $k_{2 V s s}=1,034$, hydraulic diameter $D_{H}=266,667 \mu \mathrm{m}$ and subsequently, relation (2), the inlet/outlet mean free path is found:

$$
\lambda_{i / o, V S S}=\frac{k_{2} \cdot \mu(T) \cdot \sqrt{R T}}{p_{i / o}}
$$

Consequently, based on hydraulic diameter, microchannel depth, VSS and HS model, the Knudsen number is computed with relations:

$$
K n_{i / o}=\frac{\lambda_{i / o_{-} V S S}}{D_{H}} ; K n_{i / o_{-} P}=\frac{\lambda_{i / o_{-} V S S}}{2 h} ; K n_{i / o_{H S}}=\frac{\lambda_{i / o_{-} H S}}{D_{H}} ; K n_{i / o_{-} P H S}=\frac{\lambda_{i / o_{-} H S}}{2 h} ;
$$

It is regarded that the ratio $\mathrm{a}^{*}=\mathrm{h} / \mathrm{b}=55 \times 10^{-3}$ cannot be neglected. From the specialized literature we assumed, for the case of diffusive reflection, the following coefficients: $\mathrm{a}_{1}=0,32283, \mathrm{a}_{2}=1,9925$ and $\mathrm{a}_{3}=4,2853$. Using the inlet over outlet pressure ratio $\Pi=\mathrm{p}_{\mathrm{i}} / \mathrm{p}_{\mathrm{o}}$, the mass flow (Kandlikar et al., 2005) we obtained a second-order model with help from the expression:

$$
m_{N S 2}=\frac{4 \cdot h^{4} \cdot p_{o}^{2} \cdot}{a^{*} \cdot \mu \cdot R \cdot T \cdot l}\left[\frac{a_{1}}{2} \cdot\left(\Pi^{2}-1\right)+a_{2} \cdot K n_{i / o / p r}^{p r},(\Pi-1)+a_{3} \cdot K n_{i / o / /^{p r} / H S}, \cdot \ln \Pi\right]
$$

The Nusselt number was found using the relation:

$$
N u^{-1}=\frac{\zeta^{*}}{4}+\frac{a_{1}+a_{2} \cdot \zeta^{*}+a_{3} \cdot \zeta^{* 2}}{a_{4} \cdot\left(1+3 \zeta^{*}\right)^{2}}
$$

where $\mathrm{a}_{1} \div \mathrm{a}_{4}$ are constant values.

In the expression above $\zeta^{*}$ represents a dimensionless coefficient of slip that results from:

$$
\zeta^{*}=4 \cdot K n \frac{2-\sigma}{\sigma}
$$

were $\sigma$ represent the tangential momentum accommodation coefficient, dimensionless.

We will now describe the calculus results that were obtained, for the above referenced data, by using Mathcad. The variation of the parameters Kn and $\lambda_{V S S}, \lambda_{H S}$ from relation 3 with respect to inlet pressure, is presented in Figure 24. 


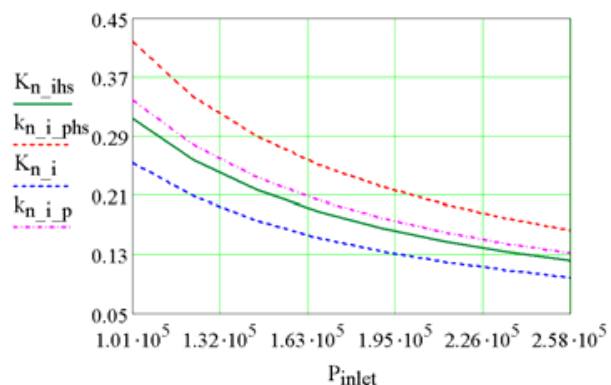

(a)

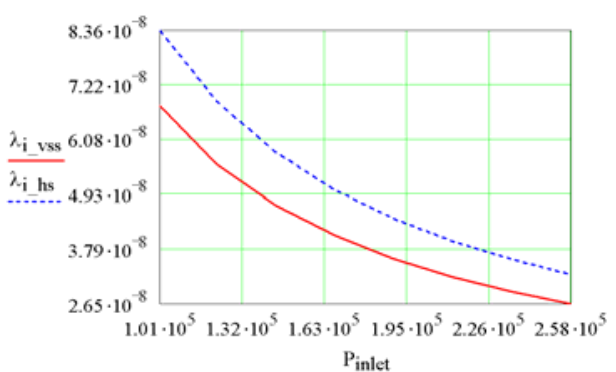

(b)

Fig. 24. Variation of parameters: (a) $K n=f\left(p_{\text {inlet }}\right)$ and (b) $\lambda_{i}=f\left(p_{\text {inlet }}\right)$

Figure 25a presents the computed mass flow $\mathrm{m}[\mathrm{kg} / \mathrm{s}]$ with respect to $\Pi$, and figure $25 \mathrm{~b}$ the results obtained for the gas: $\mathrm{He}, 0.05 \leq \mathrm{Kn}_{0} \leq 0.09, P_{o}=1.9 \cdot 105 \mathrm{~Pa}$.

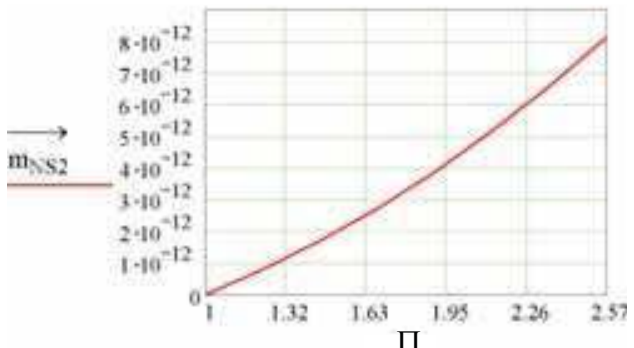

(a)

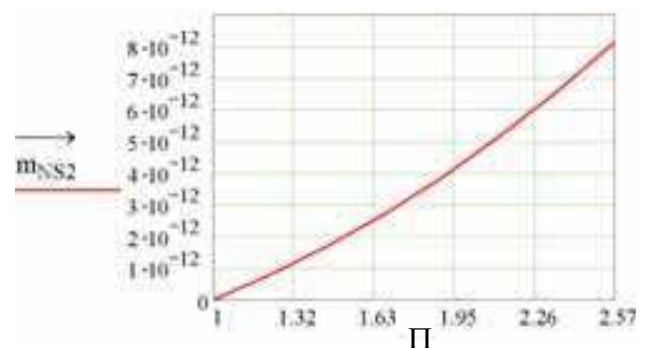

(b)

Fig. 25. Variation of the mass flow depending on П: (a) values calculated for air and (b) values ascertained for $\mathrm{He}$, by (Colin et al., 2004)

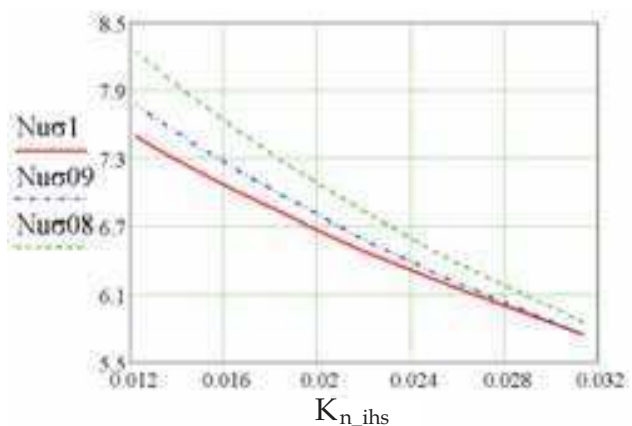

(a)

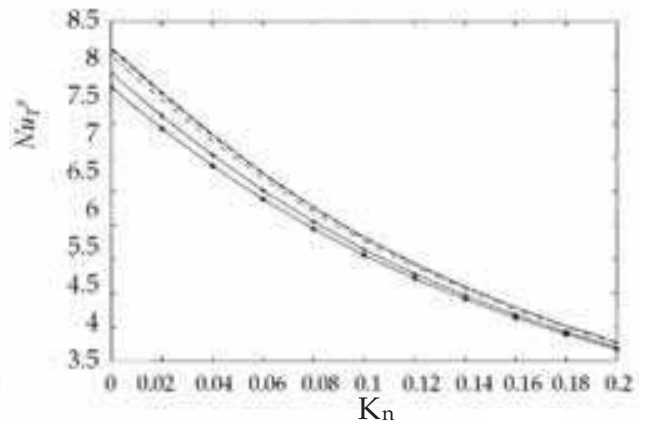

(b)

Fig. 26. Nusselt number variation depending on Knudsen number: (a) for air and (b) for air determinates by (Hadjiconstantinou \& Simek, 2002).

By analyzing the diagrams one can notice that there is, in comparison to the inlet over outlet pressure ratio, the same order of magnitude for the mass flow values and almost the same curve shape in both cases, indicating the same variation pattern. 
In order to study the Nusselt number dependency with regard to the inlet pressure but, at the same time, modify the tangential momentum accommodation coefficient, we drew, according to the previously resulted calculus, the diagrams described in figure 26a that have $\sigma=1, \sigma=0,9$ and, respectively, $\sigma=0,8$. The obtained values can be compared to the ones already existing in figure 26b, with the slip-flow calculation (constant wall), in the range $0<\mathrm{Kn}<0.2$ and, for air, $\operatorname{Pr}=0.7$.

We can make a representation of the Nusselt number variation depending on the inlet pressure. Figure 27 shows an increase in the Nusselt number together with the pressure value, fact which indicates the intensification of the convective heat exchange together with flow increase. It can also be seen a splay of the curves once the pressure increases. A higher increase in the tangential momentum accommodation leads to a lower coefficient in the Nusselt number values. Currently, several mathematical models are completed, and the VSS and HS models were adopted. The results obtained for rectangular channels with air have the same magnitude order as the ones obtained by (Kandlikar et al., 2005, Niu et al., 2007, Hadjiconstantinou \& Simek, 2002) and the shape of the graphs from Figure 23 and Figure 24 is identical with the one obtained by authors (Kandlikar et al., 2005, Niu et al., 2007, Hadjiconstantinou \& Simek, 2002). The validation of the mathematical model adopted in the present work is therefore completed.

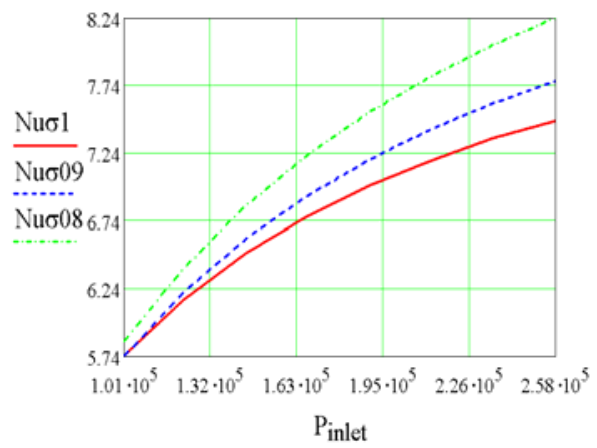

Fig. 27. Nu variation depending on $P_{\text {inlet }}$

\subsection{Heat transfer through the material interface of CPU cooling systems}

Next we will describe the heat exchange calculation at the cooler-CPU interface in the hypothesis of the adequate or inadequate thermal transfer surfaces. Heat exchange at the CPU-cooler interface can be interpreted as conductive, unidirectional with linear heat sources (Lienhard \& Lienhard, 2003, Grujicic, 2004).

It is obvious that the heat source is the core of CPU, a case in which the conducted heat flow depends on the processor type (Mihai et al.), the emanation power and the efficiency of the cooling system.

In order to maintain the CPU temperature within a stable working environment, it is desirable that we absorb a major quantity of heat emission, task which is assigned to the thermal compound paste.

The junction-to-coolant thermal resistance is (Yovanovich et al., 1997, Lasance \& Simons, 2005, Holman, 1997, Lee, 1998), in fact, composed of an internal, largely conductive 
resistance $R_{j c}$ and an external, primarily convective resistance $R_{e x}$ as it can be noticed in figure 28 .

Total thermal spreading resistance for single-chip packages:

$$
R_{T}=R_{j c}+R_{s p}+R_{e x}+R_{f l} \quad\left[\frac{K}{W}\right]
$$

were:

- The internal resistance Rjc - is encountered in the flow of dissipated heat from the active chip surface through the material used to support and bond the chip and on to the case of the integrated-circuit package;

- Spreading resistance Rsp - arising from the three-dimensional nature of heat flow in the heat spreader and heat sink base;

- External Resistance Rex - for convective cooling;

- How Resistance Rfl - the transfer of heat to a flowing gas or liquid that does not undergo phase change is an increase in the coolant temperature from the inlet temperature to an outlet temperature.

In order to calculate the heat exchange within the CPU cooling system we imply using an aluminium heat sink with a number of fins $\mathrm{N}_{\mathrm{f}}=28$, Height of fins $\mathrm{h}_{\mathrm{f}}=0.0355 \mathrm{~m}$, Thickness of fins $t_{f}=0.0013 \mathrm{~m}$, Shroud spacing $h_{b}=0.003 \mathrm{~m}$, Base-Plate dimensions $L x W=0,06 \times 0,06 \mathrm{~m}$, Power dissipation $\mathrm{P}=22.5 \mathrm{~W}$, Heat sink width $\mathrm{w}=0.06 \mathrm{~m}$, Heat sink height $\mathrm{h}_{\mathrm{hs}}=0.037 \mathrm{~m}$. We will now show the constants that were taken into account for the application that was developed in Mathcad: Ambient temperature (inside the calculator, through measurement) $\mathrm{Ta}=316 \mathrm{~K}$, Thermal conductivity of aluminium and air $\mathrm{k}_{\mathrm{Al}}=170.00 \mathrm{~W} / \mathrm{mK}$ respectively $\mathrm{k}_{\text {air }}=0.026 \mathrm{~W} / \mathrm{mK}$, air density $\rho=1.2 \mathrm{~kg} / \mathrm{m}^{3}$, heat capacity of air $C_{\mathrm{p}}=1.0 \mathrm{~kJ} / \mathrm{kgK}$, kinematics viscosity nu=1.5 $10^{-5} \mathrm{~m}^{2} / \mathrm{sec}$, Prandtl No. for air $\operatorname{Pr}=0.7$, Loss coefficient $\mathrm{K}=0.9$. In Figure 29 we show the graphical representation of the temperature variation depending on the CPU system structure when internal heat sources are present.

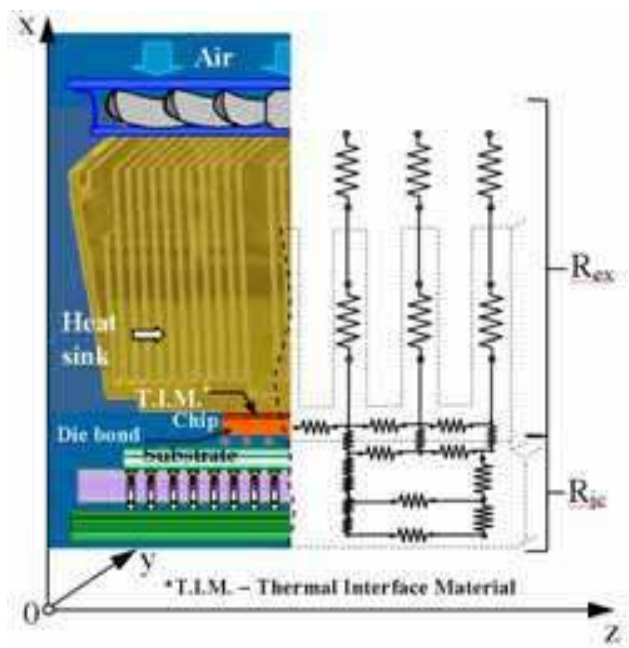

Fig. 28. Primary thermal resistances in a single-chip package 


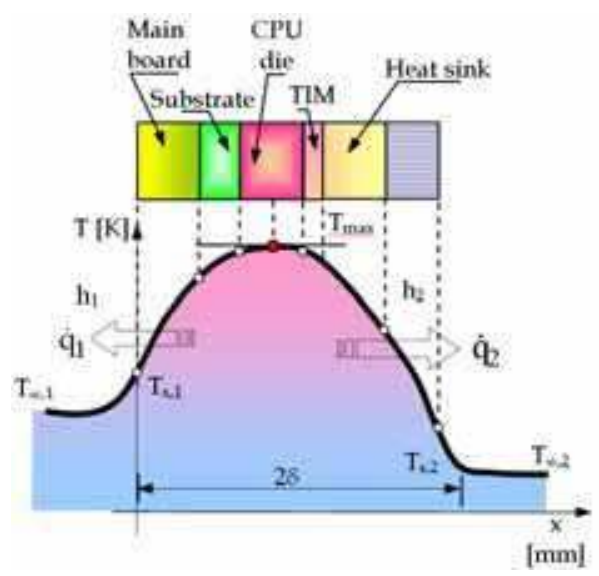

Fig. 29. Temperature variation in the CPU cooling system

In order to conduct the calculations we used the mathematical model proposed by J.P. Holman (Simons, 2004, Guenin, 2003). The area and the perimeter of the radiator are:

$$
\begin{gathered}
\text { Area }=w \cdot\left(h_{b}+h_{f}\right)-N_{f} \cdot t_{f} \cdot h_{f} \quad\left[m^{2}\right] \\
\text { Perimeter }=2 \cdot\left(w+h_{b}+h_{f}\right)+N_{f} \cdot\left(t_{f}+2 \cdot h_{f}\right) \quad[m]
\end{gathered}
$$

Calculate hydraulic diameter of heat sink/shroud passage area:

$$
D_{\text {hyd }}=\frac{4 \cdot \text { Area }}{\text { Perimeter }}[m]
$$

Holman indicates the initial use of a certain "guess value", marked as Vel. We gave this Vel an initial value $\mathrm{Vel}=0.2$. The same author indicates the use of the relation below:

$$
V=r o o t\left[\left[\operatorname{Vel}-\left[2 \cdot \frac{g \cdot P \cdot h_{h s}}{T_{a} \cdot \text { Area } \cdot C_{p} \cdot \rho\left[\left[\frac{64 \cdot n u}{V e l \cdot D_{h}}\right] \cdot \frac{h_{h s}}{D_{h}}+K\right]}\right]\right] \cdot V e l\right]
$$

Calculate Reynolds' number:

$$
\operatorname{Re}=V \cdot \frac{D_{h y d}}{n u}
$$

The frictional heating factor between two reciprocating parts in contact is:

$$
f=\frac{64}{\operatorname{Re}}
$$

Reynolds' value on the direction of air flow in the radiator has the following expression: 


$$
\operatorname{Re}_{x}=\frac{W \cdot h_{h s}}{n u}
$$

Wall heat flux:

$$
Q_{w}=\frac{P}{\left(N_{f} \cdot 2 \cdot h_{f}+w\right) \cdot h_{h s}} \quad\left[\frac{W}{m^{2}}\right]
$$

Calculate heat sink temperature rise:

$$
\Delta T=\frac{Q_{w} \cdot \frac{h_{h s}}{k_{\text {air }}}}{\left(0.6795 \cdot \operatorname{Re}_{x}\right)^{\frac{1}{3} \cdot \operatorname{Pr}^{\frac{1}{3}}}} \quad[K]
$$

Due to the fact that in the heat exchange process the convective effect steps in, Holman suggests for Nusselt number:

$$
N u_{(x)}=0.453 \cdot \operatorname{Re}_{x}^{\frac{1}{2}} \cdot \operatorname{Pr}^{\frac{1}{3}}
$$

The heat transfer coefficient:

$$
h=\frac{\int_{0}^{h_{h s}}\left[N u \cdot \frac{k_{\text {air }}}{x}\right] \cdot d x}{h_{h s}} \quad\left[\frac{W}{m^{2}}\right]
$$

Calculate fin efficiency:

$$
\eta_{f i n}=\left(h_{f}+\frac{t_{f}}{2}\right)^{\frac{3}{2}} \cdot\left(\frac{h}{k_{a l} \cdot t_{f} \cdot h_{f}}\right)^{\frac{1}{2}}
$$

In order to determine the temperature field we will (Bejan, A. \& Kraus A.D., 2003) use the Fourier equation:

$$
\frac{\partial T}{\partial \tau}=\alpha \nabla_{T}^{2}+\frac{q_{v}}{\rho c_{p}}
$$

where $q_{v}=q_{v}(x, y, z, \tau)$ represents the CPU generated source density, measured in $\left[\mathrm{W} / \mathrm{m}^{3}\right]$. By integrating the Fourier equation for the unidirectional, stationary regime, we obtain the expression of the temperature distribution in the wall:

$$
T_{(x)}=-q_{v} \frac{x^{2}}{2 k}+\left(\frac{T_{s, 2}-T_{s, 1}}{2 \delta}+\frac{q_{v} \delta}{k}\right) \cdot x+T_{s, 1} \quad[K]
$$

Were $T_{s, 1} T_{s, 2}$ being the temperatures of the exterior parts of the wall. The maximum temperature Tm in wall is achieved through $\mathrm{x}=\mathrm{x}_{\mathrm{m}}$, resulting from condition: $\frac{d T}{d x}=0$, that is: 


$$
x_{m}=\delta+\frac{k}{q_{v}} \cdot \frac{T_{s, 2}-T_{s, 1}}{2 \delta} \quad[m]
$$

The maximum temperature zone [12] is found within plate $\left(0 \leq x_{m} \leq 2 \delta\right)$, providing the following condition is observed:

$$
-1 \leq \frac{k}{2 \cdot q_{v} \cdot \delta^{2}} \cdot\left(T_{s, 2}-T_{s, 1}\right) \leq 1
$$

If we replace $x=x_{m}$ in equation (6) the maximum wall temperature is obtained:

$$
T_{\max }=\frac{q_{v} \cdot \delta^{2}}{2 k}+\frac{k}{8 \cdot q_{v} \cdot \delta^{2}}\left(T_{s, 2}-T_{s, 1}\right)^{2}+\frac{T_{s, 1}+T_{s, 2}}{2}[K]
$$

If $\mathrm{T}_{\infty, 1,2}$ being the coolant temperatures (see figure 7 ), the limit conditions of third type are:

$$
\begin{aligned}
& \text { If } \mathrm{x}=0, ;-\left.k \frac{d T}{d x}\right|_{x=0}=-h_{1}\left(T_{s, 1}-T_{\infty, 1}\right) \\
& \text { If } \mathrm{x}=2 \delta,-\left.k \frac{d T}{d x}\right|_{x=2 \delta}=h_{2}\left(T_{s, 2}-T_{\infty, 2}\right)
\end{aligned}
$$

We can determine the wall surfaces temperature [12]:

$$
\begin{aligned}
& T_{s, 1}=T_{\infty, 1}+\frac{T_{\infty, 2}-T_{\infty, 1}+2 \cdot \delta \cdot q_{v}\left(\frac{1}{h_{2}}+\frac{\delta}{k}\right)}{1+\frac{h_{1}}{h_{2}}+2 \frac{h_{1}}{k} \delta} \quad[K] \\
& T_{s, 2}=T_{\infty, 2}+\frac{T_{\infty, 1}-T_{\infty, 2}+2 \delta q_{v}\left(\frac{1}{h_{1}}+\frac{\delta}{k}\right)}{1+\frac{h_{2}}{h_{1}}+2 \frac{h_{2}}{k} \delta} \quad[K]
\end{aligned}
$$

We deem that the law of heat spreading throughout the entire volume is observed.

By first using the 1-19 expressions we calculate all the parameters that were previously mentioned. Taking into account the previously calculated measures, we determine, with relations 27 and 28 , measures $T_{\mathrm{s}, 1}$ and $\mathrm{T}_{\mathrm{s}, 2}$. With the help of relation 22 , distance $x_{\mathrm{m}}$ which refers to the CPU core, where the temperature is highest, is calculated. The next step allows establishing the maximal temperature value $\mathrm{T}_{\max }$ with relation 24 for verification of ulterior relations. Using relation 21 the maximum temperature field is determined, in plane z-y of $\mathrm{CPU}$, through insertion of two matrices, which give the distance as well as the square distance in each knot. We thus moved away from a one-dimensional transfer to a bidimensional transfer. Knowing the maximum temperature field for each point of the matrix, the same law of heat transfer applies, on direction " $x$ ". The mathematic model proposed takes into account the thermal conduction coefficient " $k$ " which is dependent of the type of material, inserting the corresponding values for each knot in the matrix. Sometimes it is common to use the transition from Cartesian coordinates to cylindrical coordinates. In order 
to validate the suggested model we shall make a comparison between the obtained results and similar cases.

\subsection{Results obtained through calculation}

Following the calculation steps, performed with the help of Mathcad, as they were described above, if we regard the internal source of heat as being directly proportional to the energy generated by each kind of processor, then we can obtain the temperature variation corresponding to the CPU die area. The calculation results, as they are described in Figure $30 \mathrm{a}$, are subsequent to the situations when TIM is unchanged. With regard to TIM imperfections taking the shape of nano or micro channels, such as those described in figure $13 \mathrm{a}$, we ascertain by means of figure $30 \mathrm{~b}$ that a temperature increment occurs, in amount of approximately $10^{\circ} \mathrm{C}$, which might lead to CPU damage.
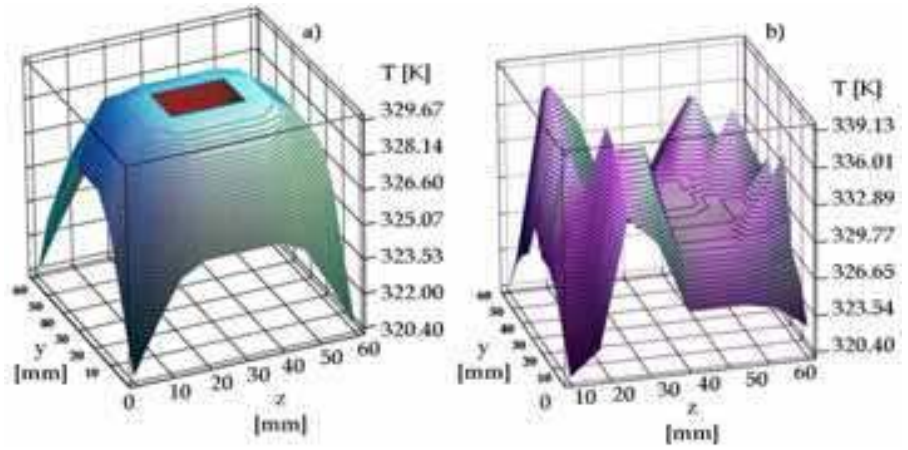

Fig. 30. The field of isotherms that corresponds to interface CPU: (a) for the same thermal conductivity coefficient and (b) in which case the coefficient of thermal conduction is altered.

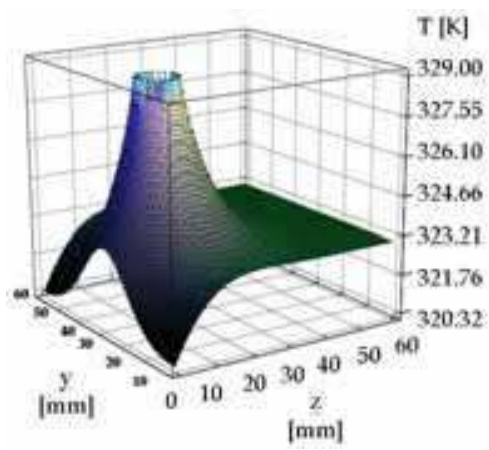

Fig. 31. Calculus in cylindrical coordinates for the field of isotherms that corresponds to for the same thermal conductivity coefficient interface TIM-CPU

Using a different calculation method, when TIM is unchanged, we obtain figure 31, thus noticing the preservation of the parabolic aspect below 323,21 K. However, the CPU area shows a conical shape that is specific to temperature increase. The values that were calculated in Mathcad are significantly close to the Cartesian model, as it can be noticed when comparing the obtained values to those comprised in figure 30a. 
In order to study the way in which the temperature changes in the CPU cooling assembly, we conducted simulations using the ANSYS environment. The obtained results (Figure 32) were compared to other similar data. An overview of the CPU die - heat sink that was obtained by (Meijer, 2009) is referred to in figure 33. We can see that there is a uniform temperature field distribution and that the maximal value obviously relates to the CPU die area.

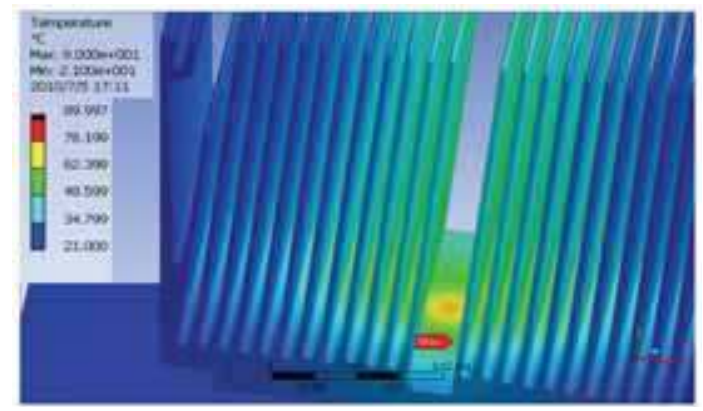

Fig. 32. The temperature field in the cooling assembly - view towards the heat sink obtained by Mihai

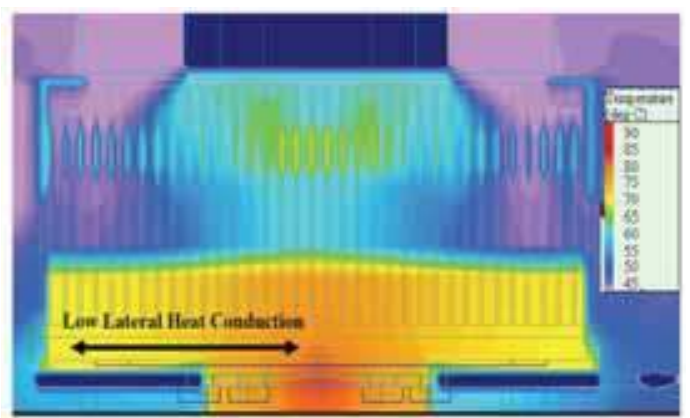

Fig. 33. Thermal modelling of the heat exchange for the CPU die - Heat Sink assembly (Meijer, 2009)

\section{Conclusions}

Considering the information that we described, we can conclude that there is a large variety of mini, macro and even nano channels inside the CPU cooling systems. In most cases they have a functional role in order to ensure the evacuation of the maximum amount of heat possible, using various criterions and effects such as Joule-Thompson or Peltier. We proved that the thermal interface material (TIM) plays an important role with regard to ensuring that the heat exchange is taking place. The AFM images of the CPU-cooler interface, showing that channels with complex geometry or stagnant regions can occur, disturbing the thermal transfer. Experimental investigations showed (figure 13) that even in an incipient phase, microchannels having $0,05 \div 0,01 \mu \mathrm{m}$ in width, form in the TIM, at depths of at most $1000 \AA$, phenomenon explained as being a result of plastic characteristics upon deposition 
on CPU surface. Although the proportions of the channels that appear accidentally due to various reasons have nanometrical sizes, they can lead to anomalies in the CPU functioning, anomalies which are caused by overheating. The purpose of the measurements conducted by laser profilometry was to verify whether profile, waviness and roughness parameters show different variations under load and in addition to evaluate dilatation for increasing temperature.

These kind of experimental determinations allow us to make the following assessments:

i. Unwanted dilatation phenomena were experimentally outlined. This leads to a "pump up" effect for the material trapped at CPU - cooler interface, phenomenon also illustrated in (Viswanath et al., 2000);

ii. No surface discontinuities (localized lack of material) were observed during or after heating;

iii. It was clearly showed that shape deviations can appear when the material is freely applied on CPU surface, before cooler positioning (figure 17), but most of these variations are flattened after cooler placement as shown in figures 21.

iv. Thermal grease surface roughness evolution was monitored and it was illustrated that its mean values show no major changes after temperature increase, which indicates a good thermal stability of the used material .

Currently, several mathematical models are completed, and the VSS and HS models were adopted, indicating the role of thermal contact resistance. The conducted calculations are relevant in this respect in order to study what happens when the TIM is deteriorated. The mathematical results clearly indicate that any strain in the interface material leads to a change in thermal contact resistance, with an effect on CPU overheating. The results obtained for rectangular channels with air have the same magnitude order as the ones obtained by (Colin, 2006) and the shape of the graphs identical with the one obtained by authors (Niu et al., 2007). The validation of the mathematical model adopted is therefore completed. In the future additional research is required with regard to TIM stability, in order to counter the development of nano or micro channels.

\section{References}

Banton, R. \& Blanchet D. (2004). Utilizing Advanced Thermal Management for the Optimization of System Compute and Bandwidth Density, Proceeding of CoolCon MEECC Conference, pp. 1-62, PRINT ISSN \#1098-7622 online ISSN \#1550-0381, Scottsdale, Arizona, (May 2004), Publisher ACM New York, NY, USA

Bejan, A. \& Kraus A.D. (2003). Heat transfer handbook, Publisher John Wiley \& Sons Inc. Hoboken, ISBN 0-471-39015-1, New Jersey, USA

Colin, S.; Lalonde, P. \& Caen, R. (2004). Validation of a Second-Order Slip Flow Model in Rectangular Microchannels, Heat Transfer Engineering, Volume 25, No. 3., (mars 2004) 23 - 30, ISSN 0145-7632 print / 1521-0537 online

Colin S. (2006). Single-phase gas flow in microchannels, In: Heat transfer and fluid flow in minichannels and microchannels, Elsevier Ltd, 9-86, ISBN: 0-0804-4527-6, Great Britain

Escher, W.; Brunschwiler, T., Michel, B. \& Poulikakos, D. (2009). Experimental Investigation of an Ultra-thin Manifold Micro-channel Heat Sink for Liquid-Cooled Chips, ASME Journal of Heat Transfer, Volume 132, Issue 8, (August 2010) 10 pages, ISSN 0022-1481

Escher, W.; Michel, B. \& Poulikakos, D. (2009). A novel high performance, ultra thin heat sink for electronics, International Journal of Heat and Fluid Flow, Volume 31, Issue 4, (August 2010), 586-598, ISSN 0142-727X 
Grujicic, M.; Zhao, C.L. \& Dusel, E.C. (2004). The effect of thermal contact resistance on heat management in the electronic packaging, Applied Surface Science, Vol. 246 (December 2004), 290-302, ISSN 0169-4332

Guenin, B. (2003). Calculations for Thermal Interface Materials, Electronics Cooling, Vol. 9, No. 3, (August 2003), 8-9, Electronic Journal

Hadjiconstantinou, N. \& Simek, O. (2002). Constant-Wall-Temperature Nusselt Number in Micro and Nano-Channels, Journal of Heat Transfer, Vol. 124, No. 2, (April 2002) 356364, ISSN 0022-1481

Holman, J.P. (1997). Heat transfer, 8th ed., published by McGraw Hill, pp. 42-44, New York:, 1997. ISBN 0-07-029666-9

Kandlikar, S. \& Grande, W. (2003). Evolution of Microchannel Flow PassagesThermohydraulic Performance and Fabrication Technology, Heat Transfer Engineering, Vol. 24, No. 1, (Mars 2003), 3-17, ISSN 1521-0537

Kandlikar, S.; Garimella, S., Li D., Colin, S., King, M. (2005). Heat transfer and fluid flow in minichannels and microchannels, Elsevier Publications, ISBN: 0-08-044527-6, Great Britain

Kavehpour, H. P.; Faghri, M., \& Asako, Y. (1997). Effects of compressibility and rarefaction on gaseous flows in microchannels, Numerical Heat Transfer part A, Volume 32, Issue 7, November 1997, 677-696, ISSN 1040-7782, Online ISSN: 1521-0634

Kim, D-K. \& Kim, S. J. (2007). Closed-form correlations for thermal optimization of microchannels, International Journal of Heat and Mass Transfer, Vol. 50, No. 25-26. (December 2007) 5318-5322, ISSN 0017-9310

Lasance, C., \& Simons, R. (2005). Advances in High-Performance Cooling For Electronics, Electronics Cooling, Vol.11, No. 4, (November 2005), 22-39, Electronic Journal

Lee, S. (1998). Calculating spreading resistance in heat sinks, Electronics Cooling, Vol. 4, No. 1., (January 1998), 30-33, Electronic Journal

Lienhard, J.H.IV. \& Lienhard, J.H.V. (2003). A heat transfer textbook, 3 rd ed., published by Phlogiston Press, ISBN/ ASIN: 0971383529, Cambridge-Massachusetts, USA

Meijer, I.; Brunschwiler T., Paredes S. \& Michel B. (2009). Advanced Thermal Packaging, IBM Research GmbH Presentation, (nov.2009), pp.1-52, Zurich Research Laboratory

Mihai, I.; Pirghie, C. \& Zegrean, V. (2010). Research Regarding Heat Exchange Through Nanometric Polysynthetic Thermal Compound to Cooler-CPU Interface, Heat Transfer Engineering, Volume 31, No. 1. (January 2010) 90 - 97, ISSN 1521-0537

Niu X.D.; Shu C. \& Chew Y.T. (2007). A thermal lattice Boltzmann model with diffuse scattering boundary condition for micro thermal flows, Computers $\mathcal{E}$ Fluids, No. 36, (March 2006) 273-281, ISSN 0045-7930

Pautsch G. (2005). Thermal Challenges in the Next Generation of Supercomputers, Proceeding of CoolCon MEECC Conference, pp. 1-83, PRINT ISSN \#1098-7622 online ISSN \#15500381, Scottsdale, Arizona, (May 2005), Publisher ACM New York, NY, USA

Simons, R.E. (2004). Simple Formulas for Estimating Thermal Spreading Resistance, Electronics Cooling, Vol. 10, No. 2, (May 2004), 8-10, Electronic Journal

Viswanath, R.; Wakharkar, V., Watwe, A., \& Lebonheur, V. (2000). Thermal Performance Challenges from Silicon to Systems, Intel Technology Journal, Vol. Q3, (Mars 2000), pp. 1-16, ISSN 1535-864X

Yovanovich, M.M.; Culham, J.R., \& Teertstra, P. (1997). Calculating Interface Resistance, Electronics Cooling, Vol. 3, No. 2, (May 1997), 24-29, Electronic Journal 


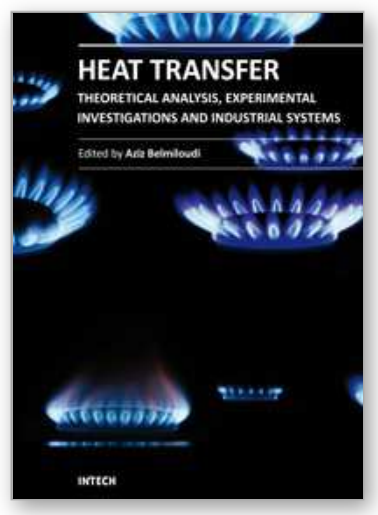

\author{
Heat Transfer - Theoretical Analysis, Experimental Investigations \\ and Industrial Systems \\ Edited by Prof. Aziz Belmiloudi
}

ISBN 978-953-307-226-5

Hard cover, 654 pages

Publisher InTech

Published online 28, January, 2011

Published in print edition January, 2011

Over the past few decades there has been a prolific increase in research and development in area of heat transfer, heat exchangers and their associated technologies. This book is a collection of current research in the above mentioned areas and discusses experimental, theoretical and calculation approaches and industrial utilizations with modern ideas and methods to study heat transfer for single and multiphase systems. The topics considered include various basic concepts of heat transfer, the fundamental modes of heat transfer (namely conduction, convection and radiation), thermophysical properties, condensation, boiling, freezing, innovative experiments, measurement analysis, theoretical models and simulations, with many real-world problems and important modern applications. The book is divided in four sections : "Heat Transfer in Micro Systems", "Boiling, Freezing and Condensation Heat Transfer", "Heat Transfer and its Assessment", "Heat Transfer Calculations", and each section discusses a wide variety of techniques, methods and applications in accordance with the subjects. The combination of theoretical and experimental investigations with many important practical applications of current interest will make this book of interest to researchers, scientists, engineers and graduate students, who make use of experimental and theoretical investigations, assessment and enhancement techniques in this multidisciplinary field as well as to researchers in mathematical modelling, computer simulations and information sciences, who make use of experimental and theoretical investigations as a means of critical assessment of models and results derived from advanced numerical simulations and improvement of the developed models and numerical methods.

\title{
How to reference
}

In order to correctly reference this scholarly work, feel free to copy and paste the following:

Ioan Mihai (2011). Heat Transfer in Minichannels and Microchannels CPU Cooling Systems, Heat Transfer Theoretical Analysis, Experimental Investigations and Industrial Systems, Prof. Aziz Belmiloudi (Ed.), ISBN: 978-953-307-226-5, InTech, Available from: http://www.intechopen.com/books/heat-transfer-theoreticalanalysis-experimental-investigations-and-industrial-systems/heat-transfer-in-minichannels-and-microchannelscpu-cooling-systems

\section{INTECH}

open science | open minds

\author{
InTech Europe \\ University Campus STeP Ri \\ Slavka Krautzeka 83/A
}

\author{
InTech China \\ Unit 405, Office Block, Hotel Equatorial Shanghai \\ No.65, Yan An Road (West), Shanghai, 200040, China
}


51000 Rijeka, Croatia

Phone: +385 (51) 770447

Fax: +385 (51) 686166

www.intechopen.com
中国上海市延安西路65号上海国际贵都大饭店办公楼 405 单元 Phone: +86-21-62489820

Fax: +86-21-62489821 
(C) 2011 The Author(s). Licensee IntechOpen. This chapter is distributed under the terms of the Creative Commons Attribution-NonCommercialShareAlike-3.0 License, which permits use, distribution and reproduction for non-commercial purposes, provided the original is properly cited and derivative works building on this content are distributed under the same license. 